\title{
Crucial Factors for the Application of Functional Nanoporous Carbon-Based Materials in Energy and Environmental Applications
}

\author{
Martin Oschatz * and Ralf Walczak \\ Department of Colloid Chemistry, Max Planck Institute of Colloids and Interfaces, Am Mühlenberg 1, \\ 14476 Potsdam (OT Golm), Germany; ralf.walczak@mpikg.mpg.de \\ * Correspondence: martin.oschatz@mpikg.mpg.de; Tel.: +49-331-5679508
}

Received: 10 September 2018; Accepted: 13 October 2018; Published: 17 October 2018

\begin{abstract}
This special issue of C-Journal of Carbon Research is dedicated to "Functional Nanoporous Carbon-Based Materials". It contains contributions reporting on the synthesis of nanoporous carbons for the adsorption of proteins, their applications in electrochemical energy storage/conversion, and on the characterization/modification of their surface chemistry. Nanoporous carbon-based materials are widely researched, but at the same time, the field is still full of unutilized potential. The atomic construction of the carbon framework, pore sizes, pore geometries, presence of heteroatoms, particle size and shape, and many other "internal screws" are available; in the end, the high potential of carbon-based materials will only be fully explored if the interplay of these crucial factors is precisely controlled. This article is a summary of what we consider important for future targeted improvement of porous carbon nanomaterials for energy and environmental applications.
\end{abstract}

Keywords: carbon-based nanomaterials; carbon synthesis; porosity; adsorption; energy storage; energy conversion; catalysis

\section{The Family of Functional Nanoporous Carbon-Based Materials}

Carbon is a fascinating chemical element. Due to its location in the periodic table of elements, it can form covalent chemical bonds with elements of very high and very low electronegativity. It is one of the elements with the highest number of existing chemical compounds. From another perspective, it can be seen that earth, atmosphere, oceans, and organisms, all have carbon cycles that are connected to each other, and carbon has an extremely high permanent "natural turnover". As science writer Eric Roston pointed out in his book The Carbon Age, "carbon is the essential building block of life that, ironically, has become humanity's great threat" [1]. The rise of the $\mathrm{CO}_{2}$ concentrations in the atmosphere is surely a serious problem associated with the imbalance and acceleration of the carbon cycle, and, especially in the 1990s, chlorofluorocarbons have been the main contributor to the growth of the hole in the ozone layer. These are just two of the many widely known examples.

Carbon-based chemical compounds obviously have a huge impact on our lives, and some of them are the fundamental reason for many current global problems-especially those related to energy and the environment. At the same time, it can be foreseen that this element will be one of the main building blocks to achieve future solutions for these problems [2,3]. Research on carbon materials for energy and environmental applications, and especially on carbon nanomaterials or "nanocarbons", is rapidly accelerating due to the promise of these materials for energy production and management, adsorption, cleaning of water and air, as catalysts or catalyst supports, in biolomedical applications, as sensors, and in many other fields [4-11].

Inorganic nanocarbons are a large family of materials. In principle, the members of this family have two general features in common: (i) They mainly consist of carbon atoms covalently bound 
to each other, and (ii) they contain textural motives on the nm-scale. Just like the bulk element modifications diamond and graphite (Figure 1a), nanocarbons can appear with different faces as well. Nanodiamonds contain mostly sp ${ }^{3}$-hybridized carbon atoms. Graphene is an extended network of $\mathrm{sp}^{2}$-bonded carbon atoms. In analogy to other nanomaterials, nanocarbons can be subdivided in 2-dimensional (graphene), 1-dimensional (carbon nanotubes), or 0-dimensional (fullerenes and nanodiamonds) compounds (Figure 1b).

The members of the nanocarbon family which are of particular interest in this special issue are nanoporous carbon- or carbon-based materials (NPCMs) [12,13]. In contrast to other $\mathrm{sp}^{2}$-dominated (i.e., "graphene-based") nanocarbons like carbon nanotubes, fullerenes, or graphene itself, nanoporous carbons have a less-defined local atomic arrangement. Substitution of graphene 6-rings by other structure motives like 5-rings, 7-rings, heteroatoms, or other defect sites leads to distortion (i.e., loss of the long-range order) and bending of the 2-dimensional atomic framework. If the density of these defects is large enough, a porous carbon framework will be the result. Such materials are, in most cases, still $\mathrm{sp}^{2}$-rich, and have high electric conductivity as well as thermal/chemical stability, but not much in common with graphene from a geometrical perspective (Figure 1c). The fundamental advantage of NPCMs is that they provide a large interface area between their internal surface and the surrounding phase. Their specific surface areas can reach up to $2000 \mathrm{~m}^{2} / \mathrm{g}$, and in some cases, even more. This property makes them attractive for applications in which physical or chemical binding of guest substances is crucial. As a personal side note, we would like to mention that the abundance of defects and numerous different binding states between carbon atoms and carbon with other atoms in these materials may be part of the answer to the question of why the surface area of a porous carbon material can exceed, in some cases, the "theoretical" $2630 \mathrm{~m}^{2} / \mathrm{g}$ (two sides of a single graphene sheet).

(a)
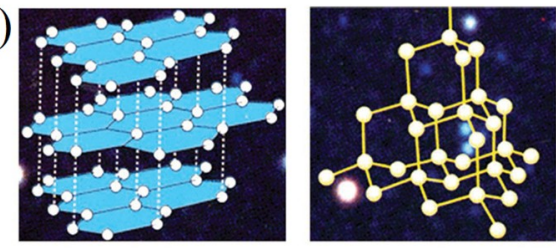

(b)
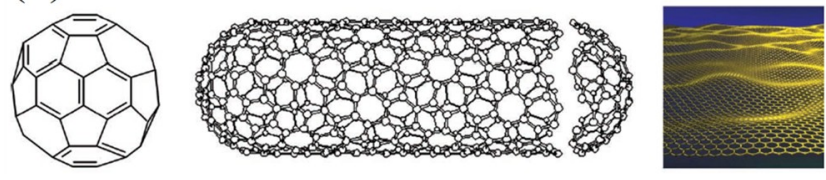

(c)
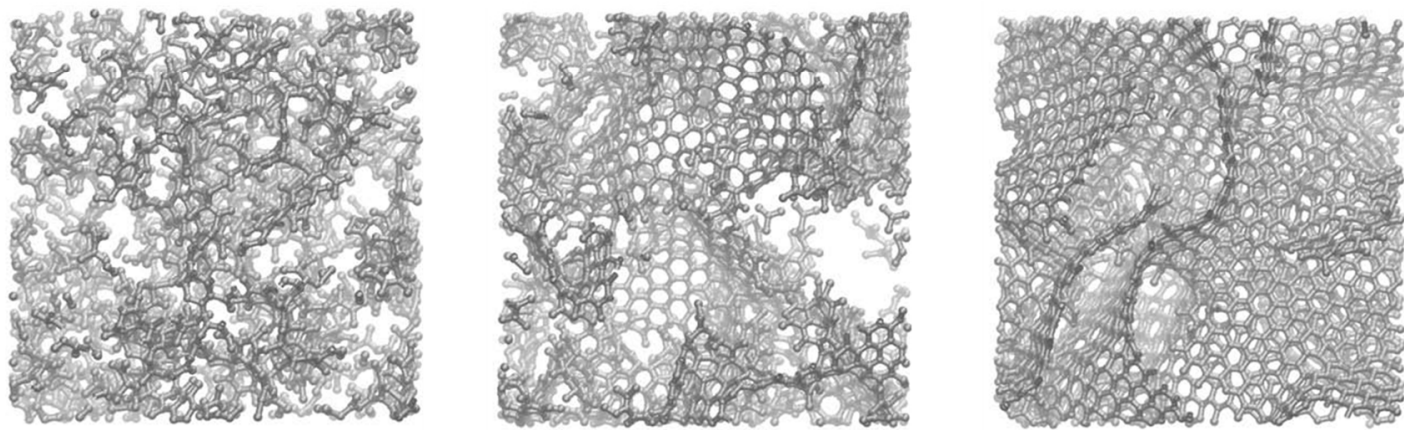

Figure 1. (a) Carbon modifications graphite (left) and diamond (right); (b) Structures of the carbon nanomaterials $\mathrm{C}_{60}$ fullerene (left), single-walled carbon nanotube (middle), and graphene (right); (c) Model atomic structures of nanoporous carbon-based materials with different degrees of carbon ordering. (a,b) adapted from [10], with permission from Wiley, 2012. (c) adapted from [14], with permission from Elsevier, 2010.

In this article, we will give a personal view on the role of functional nanoporous, carbon-based materials in energy and environmental relevant applications. We will discuss some general points that we (as inorganic chemists with rather strong synthetic background) consider as being crucial for the community to enable future targeted improvement of those materials in terms of synthesis and pore structure, but also in terms of chemical functionality. This editor's perspective will not give a full overview over all existing methods for carbon synthesis, nor will all applications where nanoporous 
carbon is used be reviewed. We will focus on some selected examples and conclude with specific problems which have a rather general character.

\section{Synthesis and Structure of Functional Inorganic Nanoporous Carbon-Based Materials}

The aim of this chapter is to give an overview over some of the most important synthesis-structure relationships that have to be considered during the production of NPCMs. At first, some general definitions are needed: What is a functional inorganic nanoporous carbon-based material? Different to the meaning of chemical functional groups (which will always be present in NPCMs to a certain extent), a "functional material" is, in our view, a material that is designed to function for a specific goal in a given application. This is, of course, a rather broad definition which can be applied to many materials on many scales and in various fields. But the definition still has to be made, and a very important message which is "hidden" within it shows one of the fundamental problems of present day materials science: A real functional material will always follow a fundamental problem that actually exists when the material is developed, and not the other way around. Of course, a really new class of materials with so far unexplored properties, or a material prepared by a novel and innovative method, does initially not have to serve a specific application, but targeted development and improvement of materials in order to provide solutions for existing problems brings real "functionality" as opposed to proposing a "new material" as the solution for a randomly-chosen "apparent problem".

The term "inorganic" implies that the material mainly consists of carbon-carbon bonds, and that there is no excessive hydrogen content. An inorganic ( $\mathrm{sp}^{2}$-based) carbon still has "benzene-like" units as the central building blocks, but only the external surface of their network may be terminated by hydrogen or other non-carbon atoms. As an example, the porous carbon structures displayed in Figure 1 are regarded as inorganic carbons, while other carbon-rich porous materials such as porous organic polymers [15,16], covalent organic frameworks [17], or metal organic frameworks [18,19] contain single organic building blocks, and are thus not considered as members of this family.

The expression "carbon-based" is somewhat related to that. Most inorganic carbon materials contain a smaller or larger amount of heteroatoms which will either be present as functional groups on the carbon surface, or will be incorporated into the graphene-like structure (Figure 2) [20,21]. As one obvious example, the edges of graphene (just like the surface of nanodiamonds) are usually terminated with hydrogen- or oxygen-containing functional groups. Other heteroatoms such as nitrogen, sulfur, phosphor, or boron can also be implemented in NPCMs [22-25]. Since in most cases, such foreign atoms have a crucial influence on the properties of the carbon-based material, we prefer the terminology "carbon-based" or "carbonaceous materials" over the simple expression "carbon materials".

From a geometrical perspective, a surface curvature may be called a "pore" when it is deeper than it is wide. The 2015 technical report of the International Union of Pure and Applied Chemistry (IUPAC) defines "nanopores" as pores with a size below $100 \mathrm{~nm}$ (in accordance with the general definition of nanomaterials). Thus, nanopores can cover the whole range from micropores (below $2 \mathrm{~nm}$ in diameter) to mesopores (2-50 nm) and up to macropores (above $50 \mathrm{~nm}$ ), and, independent of the distribution of the pore size, any inorganic carbon material containing such pores, by this definition, has to be called "nanoporous" [26]. If two or more kinds of interconnected pore systems with clearly-distinguishable size are present in one material, this carbon has "hierarchical" porosity $[27,28]$. In general, "hierarchy" describes a ranking of, for example, items, ideas, values, concepts, or organizations [29]. Following from that, a material has to combine entities, compositions, and/or geometrical structures to form compartments or paths of matter with different properties to be called hierarchical. In spite of this quite clear definition, the term is often misused in the literature, and porous materials which obviously do not comply with it are frequently called hierarchical. 
(a)

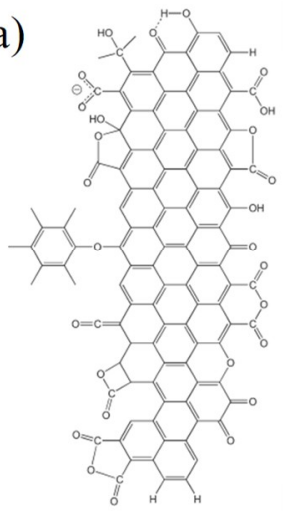

(b)

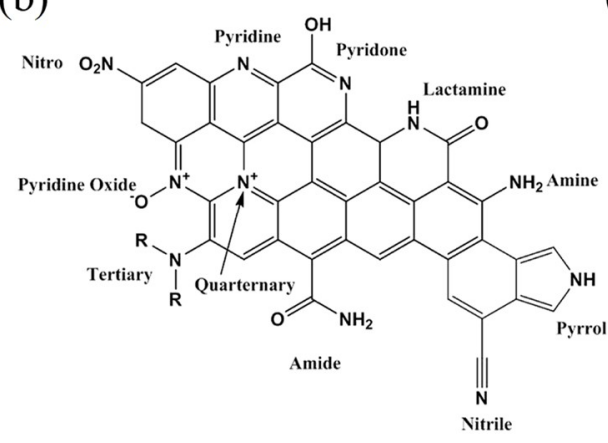

(c)

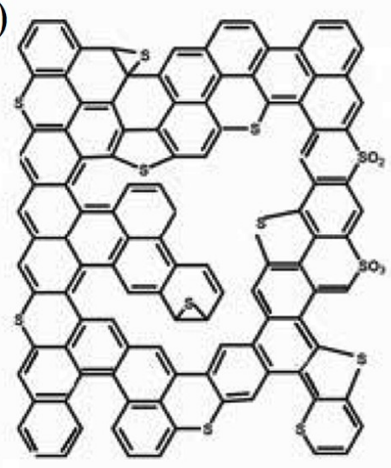

Figure 2. Examples for (a) oxygen-, (b) nitrogen-, and (c) sulfur-containing structure motives in nanoporous carbon-based materials. (a) reproduced from [21], with permission from Wiley, 2008; (b) reproduced from [30], with permission from RSC Publishing, 2015; (c) reproduced from [31], with permission from American Chemical Society, 2012.

\subsection{Synthesis of Functional Carbon-Based Materials with Different Pore Structures}

The synthesis NPCMs usually includes (i) the (in most cases thermal) conversion ("carbonization") of an organic carbon precursor material, and (ii) the generation of nanopores [12]. Widely applied precursors are carbon-rich polymers from biomass, carbohydrates, or phenolic resins. Energy efficient alternatives to simple heating are hydrothermal carbonization [32-34] and ball milling [35-37], to mention just two examples with great potential for more sustainable future carbonization processes. It should also be generally noted that most of the previously-developed synthesis protocols for NPCMs are "top-down-like". This means that they are based on the decomposition and atomic reorganization of a high molecular mass polymer. This leads in general to the formation of NPCMs with heterogeneous atomic constructions. In contrast, "bottom-up-like" approaches starting from molecular building blocks provide a promising pathway to enable more precise control over the atomic structure (see Section 2.2), and thus, to introduce defined chemical functionality [38-40].

Besides the atomic construction and the porosity (as discussed in the chapters below), the morphology of the resulting NPCMs is another critical aspect that has to be considered when choosing the synthetic protocol. Macroscopic and microscopic morphology, as well as the resulting mechanical properties of the NPCMs, are, in many cases, crucial factors for the properties in a given application and for further engineering [41-43]. However, only in a very few cases the question of whether a powder/monolithic material, a spherical/high aspect ratio material, or maybe even a thin film NPCM, is desired, can be completely decoupled from the nanoporosity formation. One reason for this is that the morphology is often crucial for mass transport during synthesis. Like the macroscopic morphology, the nanoporosity (mainly the mesoporosity) of NPCMs can appear in different morphologies and geometries as well. Examples are ordered mesopores of different geometries [44-46], aerogel-type mesopores [47,48], or foam-type mesopores [49,50], just to mention a few (Figure 3a). The fact that nanopore size is not the only crucial factor that determines the properties of NPCMs, but that pore geometry and pore connectivity also play an important role, is often overlooked. For example, it is obviously useless to tailor the pore size of carbon materials for the adsorption of a certain guest species if the entries of the pores are too small to be passed by these objects.

As another personal side note, we would like to mention that a synthesis protocol towards NPCMs is not "sustainable" simply because a renewable carbon source or a waste product is utilized as the precursor. Of course, it seems at first glance more attractive to use, for example, banana peels or coconut shells as carbon sources instead of synthetic polymers, but there are many more aspects to consider per mass of produced product, such as the overall energy consumption during synthesis, the carbon atom efficiency, the amount of liquid waste and gaseous byproducts produced, the consumption and potential recycling of chemicals, safety issues, and others in order to rate the real sustainability of 
a synthetic protocol. "The 12 Principles of Green Chemistry" are a useful guide for evaluating the sustainability of a newly developed synthesis process [51]. One class of precursors that should always be handled with care is food and food components such as proteins, bovine milk, sugars, and others. Food wastes or byproducts of the food industry are surely less problematic [52].

One class of precursor materials for NPCMs which is currently attracting increasing attention is metal-organic frameworks (MOFs) $[53,54]$. While their metallic centers are utilized as porogen, the organic linkers serve as a carbon source. Potentially present functional groups in the linker molecules can also lead to heteroatom-doped NPCMs $[55,56]$. The approach to just produce NPCMs by carbonization of MOFs has, from our point of view, some drawbacks, as similar materials can in principle be obtained from rather cheap and sustainable precursors as well. MOF-derived carbons can be useful if the resulting NPCMs or metal(oxide)-containing NPCMs are suitable as model substances for academic purposes. One particular advantage of such materials is that the shape of the MOF crystals or particles can usually be precisely transferred to the resulting products, and hence, this is a particularly suitable system for the pore shape-controlled synthesis of carbon materials (Figure 3b) $[57,58]$. However, this phenomenon of "shape conservation" (i.e., the macro- and mesoscopically conformal precursor-to-carbon transformation) is quite common also for many other carbon precursors such as carbides or polymers [28,59].

Another class of precursor materials for the production of nanoporous carbons at theoretically $100 \%$ atomic efficiency is metal or semi-metal carbides. So-called carbide-derived carbons (CDCs) can be prepared by the removal of metal atoms from carbides, most often using a stream of hot chlorine gas (Figure 3c) [60,61]. This synthesis is, of course, hardly scalable, and can also not be regarded as being sustainable, but the resulting materials can have a very well-defined porosity and carbon structures which are a function of the carbon distribution in the carbide precursor and the temperature of the chlorine treatment [62,63]. In consequence, CDCs are of upmost academic interest, and have been applied as model substances in many studies over recent years in order to get a more profound understanding of the interaction mechanisms between various guest species and carbon pores of different sizes [64-68]. Recently, it has been reported that nitrogen-doped CDCs can be synthesized by chlorine treatment of silicon carbonitride precursors or titanium carbide nanoparticles [69,70].
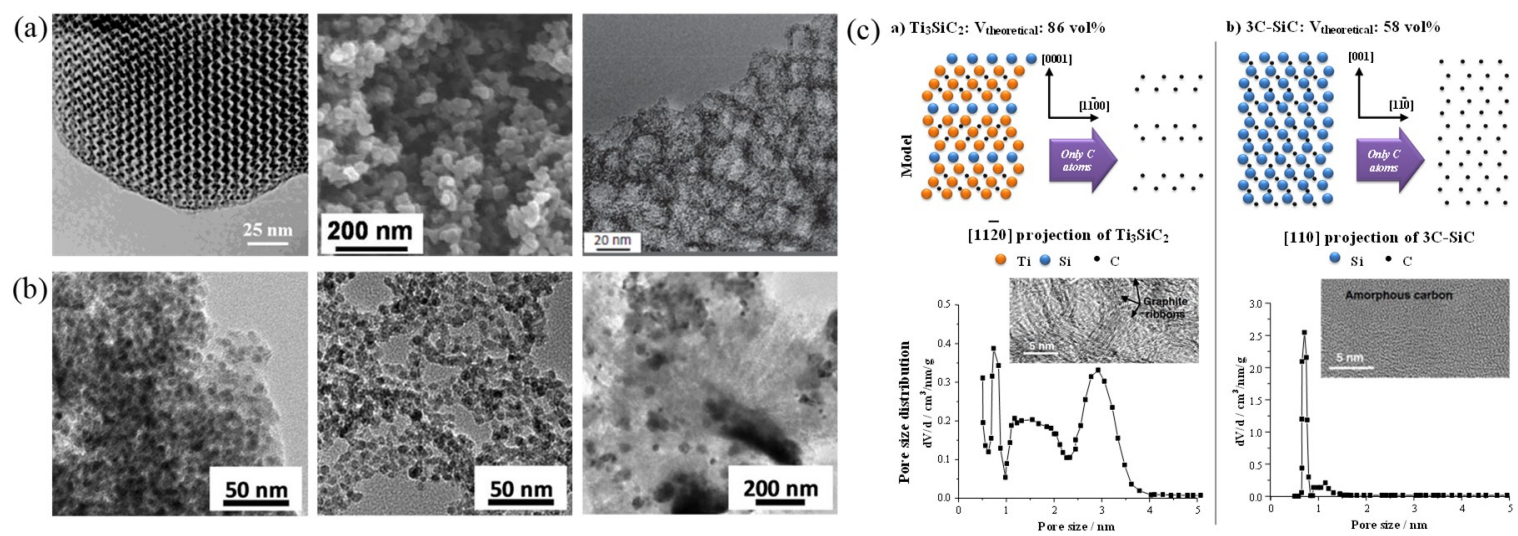

Figure 3. (a) Transmission or scanning electron microscopy (TEM and SEM) images of an ordered mesoporouscarbon (left) [44], a carbon aerogel (middle) [47], and a mesoporous carbon foam (right) [49]; (b) TEM images of iron/carbon materials derived from Fe-metal-organic framework (Fe-MOF) precursors with different porosity (left: MOF xerogel; middle: MOF aerogel; right: microporous MOF) [57]; (c) Schematic of the atomic structure of $\mathrm{Ti}_{3} \mathrm{SiC}_{2}$ (left) and $3 \mathrm{C}-\mathrm{SiC}$ (right) and the corresponding carbide-derived carbon (CDC) structures with TEM images and pore size distributions after halogen treatment [60]. (a) reproduced from [44], with permission from Wiley, 2001, from [47], with permission from RSC Publishing, 2014, and from [49], with permission from Wiley, 2013; (b) reproduced from [57], with permission from RSC Publishing, 2017; (c) reproduced from [60], with permission from Wiley, 2011. 
Considering again the commonly-applied, metal-free polymeric carbon precursors, the generation of pores can take place either in parallel or after the carbonization step. If the porosity is introduced after carbonization, this is called "activation" [71]. The resulting carbon materials are called "activated carbons". Activation is in most cases performed either by physical (etching carbon with $\mathrm{CO}_{2}$, steam or air at high temperatures) [72,73] or chemical (etching carbon with $\mathrm{ZnCl}_{2}, \mathrm{KOH}$ or other chemicals) $[74,75]$ methods. Activation is a widely-applied method for the generation of micropores and high surface areas. As activation is a rather simple process for porosity generation, activated carbons are by far the most relevant class of porous carbon materials for industrial applications. In some cases, however, the resulting carbons suffer from ill-defined pore connectivity and relatively broad size distribution. Activation is also not a suitable method for the synthesis of well-defined mesopores.

If the porosity is introduced in parallel to the carbonization step, usually a "templating" approach has to be applied, i.e., a spaceholder is present during the carbonization and either removed in parallel or in an additional synthesis step [13]. Such a template can either be a hard template (an inorganic "mold" that has to be removed after carbonization, Figure 4, top) [76,77], a soft-template (an assembly of amphiphilic molecules that is removed during carbonization, Figure 4, bottom) [45,78], or a sacrificial template (a solid mold that is removed by thermal decomposition in parallel to the carbonization) [79]. In this way, the porosity of the finally obtained NPCM will be dictated by the texture of the template. Obviously, the combination of multiple templating approaches, or the combination of templating approaches with etching, are the methods of choice for the synthesis of hierarchical materials $[46,80,81]$. Templating is usually more versatile in terms of the resulting pore systems, and has higher atomic efficiency (i.e., the carbon yield relative to the carbon within the precursor) in comparison with activation, as no carbon is lost due to etching. However, it has the significant disadvantage that a template has to be synthesized, to be engineered into the composite with the carbon precursor, and to be removed after carbonization. It is thus not surprising that the majority of industrially relevant NPCMs are activated carbons, whereas a large part of the materials utilized in academic research are templated carbons which are more difficult to synthesize, but in most cases have a rather defined pore structure-especially when mesopores are considered.

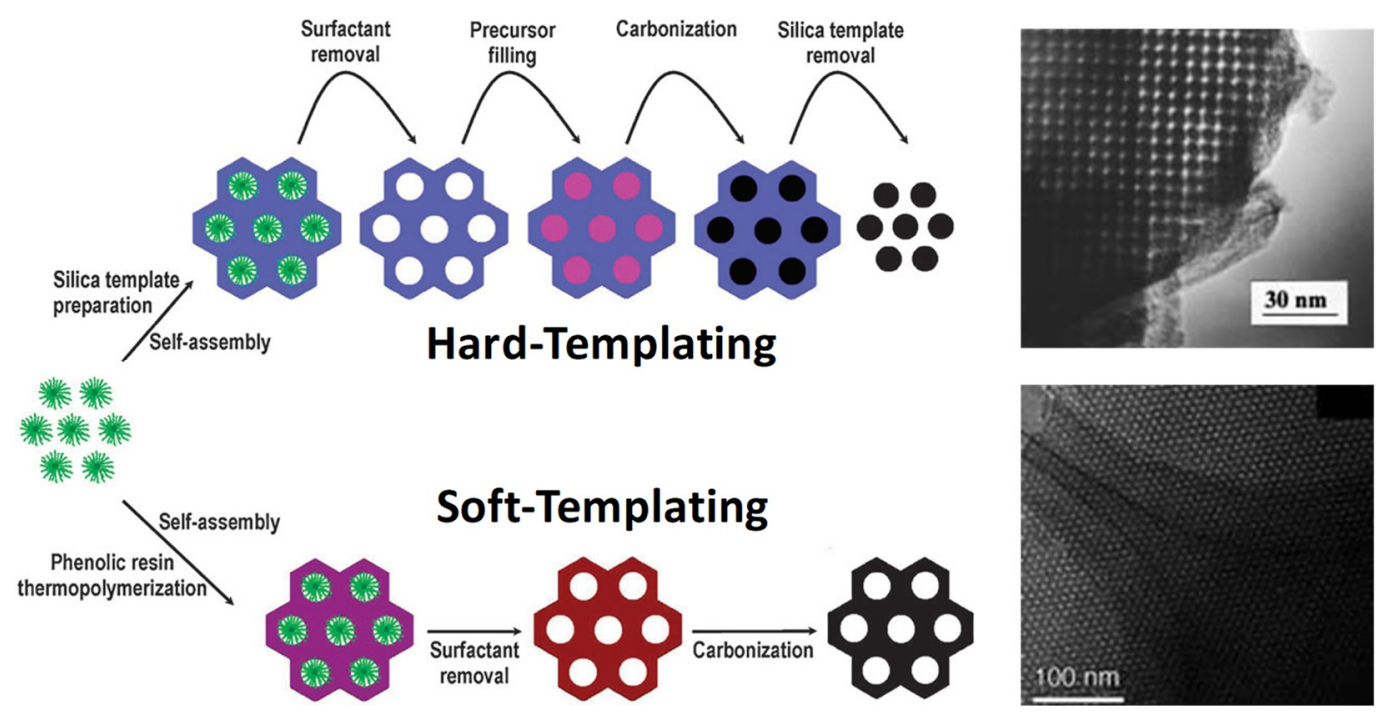

Figure 4. Schematics of hard- and soft-templating routes for the synthesis of ordered mesoporous carbon materials [82] and transmission electron microscopy images of hard-templated carbon (top) [83] and soft-templated carbon (bottom) [78]. Figures adapted/reproduced from [78], with permission from Wiley, 2005, [83], with permission from American Chemical Society, 1999, and [82], with permission from RSC Publishing, 2013.

Some recently reported synthesis methods such as salt-templating [84,85], or the removal of oxidic templates by reductive carbochlorination [86,87], are potentially scalable synthesis protocols 
for well-defined mesoporous carbons, because the mesopore templates are either recyclable without huge additional efforts, or are recovered as high-value byproducts, respectively. In some cases, defined nanopores can also be generated without the use of templates or activation. For smaller micropores, this can be achieved with bottom-up approaches if a defined condensation reaction between organic precursor molecules takes place leading to the formation of narrow porosity [88]. Template- and activation-free generation of mesoporous carbon materials can be achieved by the structurally-conformal transformation of mesoporous carbon precursor polymers such as aerogels or xerogels $[89,90]$.

\subsection{Controlling Atomic Construction and Introducing Chemical Functionality into Nanoporous Carbon-Based Materials}

A network of carbon atoms in NPCMs obtained from typical precursors is, in most cases, characterized by relatively low local order in terms of hybridization/connection motives, aromaticity, network extensions, and other properties. This, in turn, is the reason for the large density of defect sites, structure distortion, and the origin of the mainly amorphous character of most NPCMs. Such materials are usually not very oxidation-resistant. There remain two possibilities to achieve a certain degree of control over the local atomic arrangement of carbon atoms in the NPCMs, namely, the carbonization conditions (most importantly the temperature), and the chemical structure of the applied precursor. A higher synthesis temperature usually leads to enhanced carbon ordering, that is, the preferred orientation of $\mathrm{sp}^{2}$-hybridized carbon atoms in six-rings, and an increase in the graphitic-like domains in the obtained carbon materials [91,92]. This increase in crystallinity is then typically accompanied with a decrease in porosity. Such "graphitization" can also occur at low temperatures in the presence of catalysts such as iron $[93,94]$.

In recent years, it has been more and more accepted that not only the pore structure and the degree of graphitization are crucial for the properties of NPCMs in energy and environmental applications, but that the chemical functionality may be an even more crucial parameter. In particular, the insertion of heteroatoms into the carbon network or on its surface can change important properties such as the oxidation resistance, electric conductivity, and the strength/mechanism of interaction with guest species in general $[22,95]$. Obviously it is crucial to control the chemical construction and density of such sites as precisely as possible in order to achieve sufficient control over the properties of the resulting materials in a given application [96,97]. In many cases, post-synthetic modification of existing carbon surface groups is applied to introduce heteroatoms. For example, ammonia treatment or treatment in boiling nitric acid/hot air can be used to introduce nitrogen- and oxygen-containing functional groups, respectively $[98,99]$. However, as NPCMs are, in most cases, chemically heterogeneous materials, such post-synthesis treatments often do not allow sufficiently precise control over the nature and density of heteroatoms introduced. From that perspective, it seems favorable to utilize controlled condensation of molecular or polymeric precursors, which already contain the desired structure motives for the NPCM synthesis $[38,40,88]$ (Figure $5 a$ ). In such a way, a more precise control over the nature of heteroatom-sites is possible, and in addition, the density of the introduced heteroatoms can be extremely high. Such heteroatom-rich carbon materials with well-ordered, local atomic arrangements obtained from pre-organized molecular precursors are usually very oxidation resistant ("noble", Figure 5b), and if their pore size is in the range of the molecular dimensions, they have a particularly strong affinity to polar guest species such as water, carbon dioxide, or even nitrogen $[88,100]$. These properties are quite uncommon for pure NPCMs, and cannot be achieved by simple post-synthesis modification treatments. 
(a)
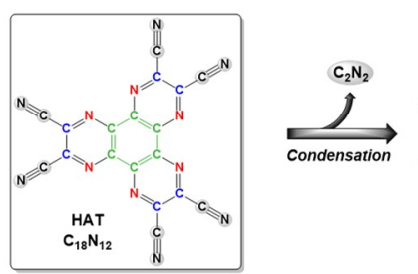

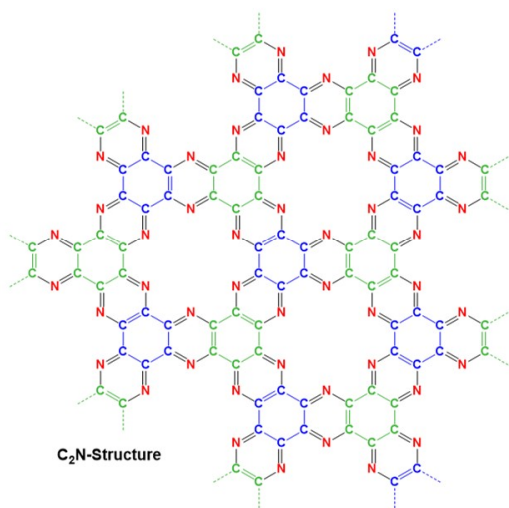

(b)

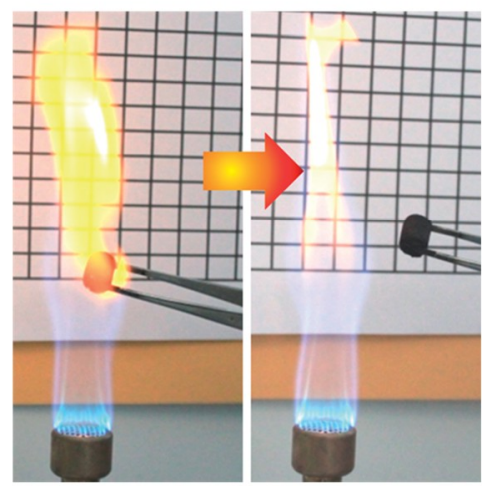

Figure 5. (a) Idealized model for the formation of a $\mathrm{C}_{2} \mathrm{~N}$-type structure by condensation of a hexaazatriphenylene-hexacarbonitrile precursor [88] and (b) fire-retardancy of a "noble" carbonaceous foam shown by repeatedly firing the sample using a butane/propane gas burner [101]. (a) reproduced from [88], with permission from Wiley, 2018; (b) reproduced from [101], with permission from RSC Publishing, 2013.

\subsection{Characterization and Modelling of the Structure of Nanoporous Carbon-Based Materials}

Scientists working with NPCMs often face one particular problem, that is, the rather difficult determination of the structure of these materials which results from their amorphous character and limited local atomic ordering (highly porous zeolite-templated carbon materials [102] can be regarded as an exception here). Modeling of surface phenomena on other porous materials like zeolites, ordered mesoporous silica, or metal-organic frameworks, is more straightforward, since they are crystalline and/or have a precisely predictable surface chemistry. This is quite different in NPCMs, and it is therefore not surprising that far fewer models are available for the atomic construction of such materials. One particular field in which useful models have been developed over the last year is the theoretical work done on ion storage mechanisms in microporous carbon materials (Figure 6) [103-106]. Such studies will also be increasingly important in other fields in the near future, because only with a reliable and realistic image of the atomic construction, surface, and bulk phenomena in NPCMs, they can be properly understood.

(a)

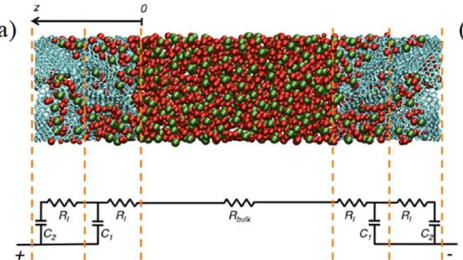

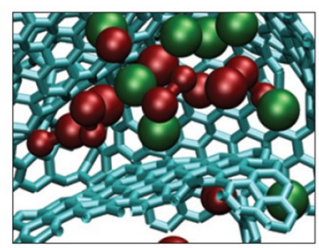
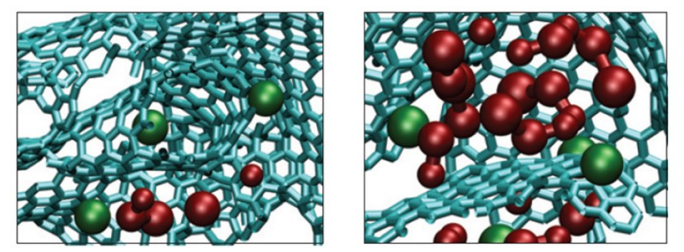

Figure 6. (a) Simulation of 1-butyl-3-methylimidazolium hexafluorophosphate $\left(\mathrm{BMI}^{\left.-\mathrm{PF}_{6}\right)}\right.$ ) ionic liquid electrolyte surrounded by two porous carbon electrodes held at constant electrical potentials (blue: $\mathrm{C}-\mathrm{C}$ bonds; red: the three sites of $\mathrm{BMI}^{+}$; green: $\mathrm{PF}_{6}{ }^{-}$ions) and equivalent electric circuit used to model the simulation setup [103]. (b) Typical structure of the ionic liquid inside the electrified pores of the carbon (left: local structure near a positive surface at $+0.5 \mathrm{~V}$; middle: a single anion in a nanotube-like pore positively polarized at $+0.5 \mathrm{~V}$; right: local structure near a negative surface at $-0.5 \mathrm{~V}$ ) [104]. (a) reproduced from [103], with permission from American Chemical Society, 2014; (b) reproduced from [104], with permission from Springer Nature, 2012.

Another field into which theoretical modeling of carbon surfaces has led to major advantages in data analysis is gas physisorption. Until the 1990s, gas adsorption isotherms (probably the most widely-applied method for the characterization of NPCMs) have mainly been analyzed with classical methods such as the Brunauer, Emmett, and Teller (BET) model to calculate specific surface area [107], or the Barrett, Joyner, and Halenda $(\mathrm{BJH})$ model to calculate pore size distributions [108]. However, 
especially the latter suffers from the disadvantage of not being applicable to micropores, and it also does not take into consideration that the phase diagram of the pore fluid shifts under nanoconfinement [109]. Nowadays, more realistic textural properties of NPCMs can be obtained by applying advanced density functional theory (DFT) models to the experimentally-obtained isotherms [110]. These tools are working for micropore as well as for mesopore analysis, and can give more reliable porosity analyses. Meanwhile, such methods are available for analysis of adsorption as well as for desorption branches, and also for different adsorptives such as nitrogen, carbon dioxide, or argon at various measurement temperatures. As the surface of NPCMs is neither structurally nor energetically homogeneous, the introduction of quenched solid-DFT (QSDFT) or 2-dimensional-non local-DFT (2D-NLDFT) methods, which take this energetic heterogeneity and geometrical corrugation into account, was another major step towards the accurate analysis of physisorption isotherms of such materials [111,112]. However, one aspect that is currently becoming more and more critical is that highly heteroatom-rich carbon materials are often analyzed with these tools, and that adsorptives with a significant quadrupole moment such as carbon dioxide and nitrogen can have a high binding potential to specific structure motives in the doped carbon materials. In some cases (like for carbon dioxide), these isotherms are then analyzed with a DFT model that does not take such significant heterogeneities in the electron density distributions into account, which might lead to significant deviations (usually underestimation) of the calculated pore sizes from the "real" values. Hence, there are many reasons to recommend the use of an adsorptive with low quadrupole moment such as argon [113]. This is especially crucial when very heteroatom-rich materials are characterized.

From these examples it can be seen that a positive aspect of the amorphous character of NPCMs is that scientists became increasingly interested in developing novel methods and advanced models to predict a realistic image of their atomic construction and/or their pore structure. Such tools and models have been established for gas physisorption [67,112], Raman spectroscopy [114-116], transmission electron microscopy [91,117], X-ray scattering [92], quenched molecular dynamics [14], and many more characterization techniques. The developed models are often compared with results obtained by other methods to complement each other. Due to the increasing interest in heteroatom-doped carbon materials, element-specific characterization methods such as X-ray photoelectron spectroscopy (XPS), electron energy loss spectroscopy, or simply thermal analysis coupled with mass spectrometry are also of increasing interest. In most publications, newly-developed carbon materials are well characterized with many of these analytical tools. Careful analysis and data interpretation are indeed of crucial importance in order to find true structure-performance relationships for a given application. Without a clear image of the carbon structure, such attempts will give misleading results and conclusions. On the other hand, NPCMs with sharply-defined pore systems and chemical properties can also be employed to show the full potential of a newly-developed characterization method or to illuminate potentially established misinterpretation of analytical data.

Clearly, the number of available characterization techniques for porous carbon nanomaterials has significantly increased in recent years. There are more and more novel characterization tools, measuring techniques, and data evaluation models available giving us a more precise view of this class of usually very amorphous materials. There is, however, still a lot of work to do on both the technological side, but also (and maybe even more importantly) on the data evaluation side. It is not enough to have well measured Raman or XPS spectra of a carbon material if the spectra are not accurately fitted and if incorrect models and/or data interpretation is applied. Especially in Raman spectroscopy, the D-band is often misinterpreted. In a perfectly ordered (i.e., crystalline) carbon structure, such as CNTs, this "disorder-induced" band indeed indicates the presence of defects in the graphitic structure. However, the interpretation of such spectra is very different for nanoporous carbon-based materials with low local ordering. In most cases, a NPCM material with a higher degree of carbon ordering (i.e., less but still present amorphous character) will contain more graphitic nanodomains. As a consequence, an increasing $\mathrm{I}_{\mathrm{D}} / \mathrm{I}_{\mathrm{G}}$ ratio will not indicate more defects, but, in contrast, a carbon structure with higher carbon ordering as the D-band is caused by the edges 
(defects) of graphitic nanocrytallites [91]. If a physisorption isotherm shows obvious percolation effects, then the pore size distribution should not be calculated from the desorption branch. Such problems are not only an issue for characterization, but probably even more for the application of NPCMs. More and more record numbers are reported, but it remains in some casesunclear how these numbers have been calculated. As for many other families of materials, the world-wide standardization of characterization data analysis remains a serious issue for NPCMs, because as long as two similar curves are analyzed in different ways, the interpretations and conclusions drawn from them can spread over a too broad range.

\section{Energy and Environmental Applications of Functional Nanoporous Carbon-Based Materials}

It is literally impossible to give a complete overview of the role of NPCMs in all energyand environmentally-relevant applications, as they range from gas to protein adsorption and from electrical double-layer capacitors to battery electrodes. In catalysis applications, NPCMs can be utilized as supports for active species (in most cases metal nanoparticles) [118], but their intrinsic structures can also work as the catalytically-active species themselves [119-121]. A nanoporous carbon material that is to be applied for the selective separation of $\mathrm{CO}_{2}$ at low concentration (e.g., from flue gas or air) $[30,122]$ has to have different properties to a material that is applied for high pressure $\mathrm{CO}_{2}$ storage [123] The pore sizes and surface properties needed for adsorption of dye molecules [124], heavy metal ions [125], or proteins [126] from solution, will obviously differ quite significantly. The requirements for a good supercapacitor electrode material [127] are very different to those for a suitable carbon material for hosting sulfur in lithium-sulfur battery cathodes [128]. These are just a few examples on the very different requirements that NPCMs have to fulfill even in not too different applications. For sure, a very broad set of parameters has to be accurately balanced in order to optimize materials and to conclude reliable structure-performance relationships. Coming back to what has been mentioned above, this is the fundamental reason why the solution has to follow the problem, not the other way around. In this chapter, we will only discuss some very general examples of structure-performance relationships of NPCMs in energy and environmental applications which we believe to be important in the near future, and will give a personal view on the way this field may go forward in the coming years.

\subsection{The Importance of Carbon-Guest Interactions}

What most of the applications of NPCMs have in common is that at least one of the fundamental steps is dominated by chemical or physical interactions at the interface between carbon surface and the surrounding species. Such a process can be a physical adsorption, the chemisorption/activation of an atom or molecule, energy/electron/ion transfer with an electrolyte, or even a nucleation process starting from the carbon surface. There are two apparent options available to influence these processes. The first (extrinsic) is the overall operation conditions like properties/concentration/pressure of the guest species, contact time, temperature, the electric potential of a carbonaceous electrode, and others. The second option is to modify the intrinsic properties of the NPCMs, most importantly porosity and chemical functionality. Which of these two "internal regulation screws" is most important can differ significantly from application to application. In many cases both of them play a role. When a selective interaction with a certain guest species is required (e.g., in selective gas capture or selective removal of ions/molecules from aqueous solution), then the chemical functionality seems to be the more crucial factor at first glance because chemical interactions with energies in the range of ionic/covalent bonds or hydrogen bridges are energetically stronger than purely physical van der Waals forces. At the same time, it should not be overlooked that the chemical interactions have to be, in most cases, reversible at reasonable energetic effort and on a relevant time scale.

For example, it is well known that heteroatom-containing groups (most often with nitrogen) can lead to stronger adsorption of carbon dioxide [24,129], to higher energy storage in supercapacitors [36,130-132], and to more efficient polysulfide retention in lithium-sulfur batteries [133-135] (Figure 7). In the most extreme cases, the electron density and distribution in the guest species is changed so drastically that 
a carbon-based material can act as a catalyst for their conversion $[121,136]$. Until a few years ago, such strong adsorption was believed to be possible only on the surfaces of metals and metal oxides, but it has recently been explored that (particularly heteroatom-doped) NPCMs can also provide catalytic activity without the addition of any metal. Even if a catalytically-active species like a metal is deposited as the guest species on the carbon surface (the NPCM is then acting as a so-called "support"), the atomic construction of the carbon is still crucial, as it will have a strong effect on the physical and electronic interactions with the molecules to be converted and with the catalytically active species $[137,138]$. In other words, NPCMs (no matter if heteroatom-doped or not) are, in most cases, "non-innocent" catalyst supports. Heteroatoms in NPCMs in particular can provide additional control over the phase and size of the deposited species, and can even enable the stabilization of very small metal clusters or single atoms on carbonaceous supports-comparable to ligands surrounding a metal center in homogeneous catalysts [100,139].
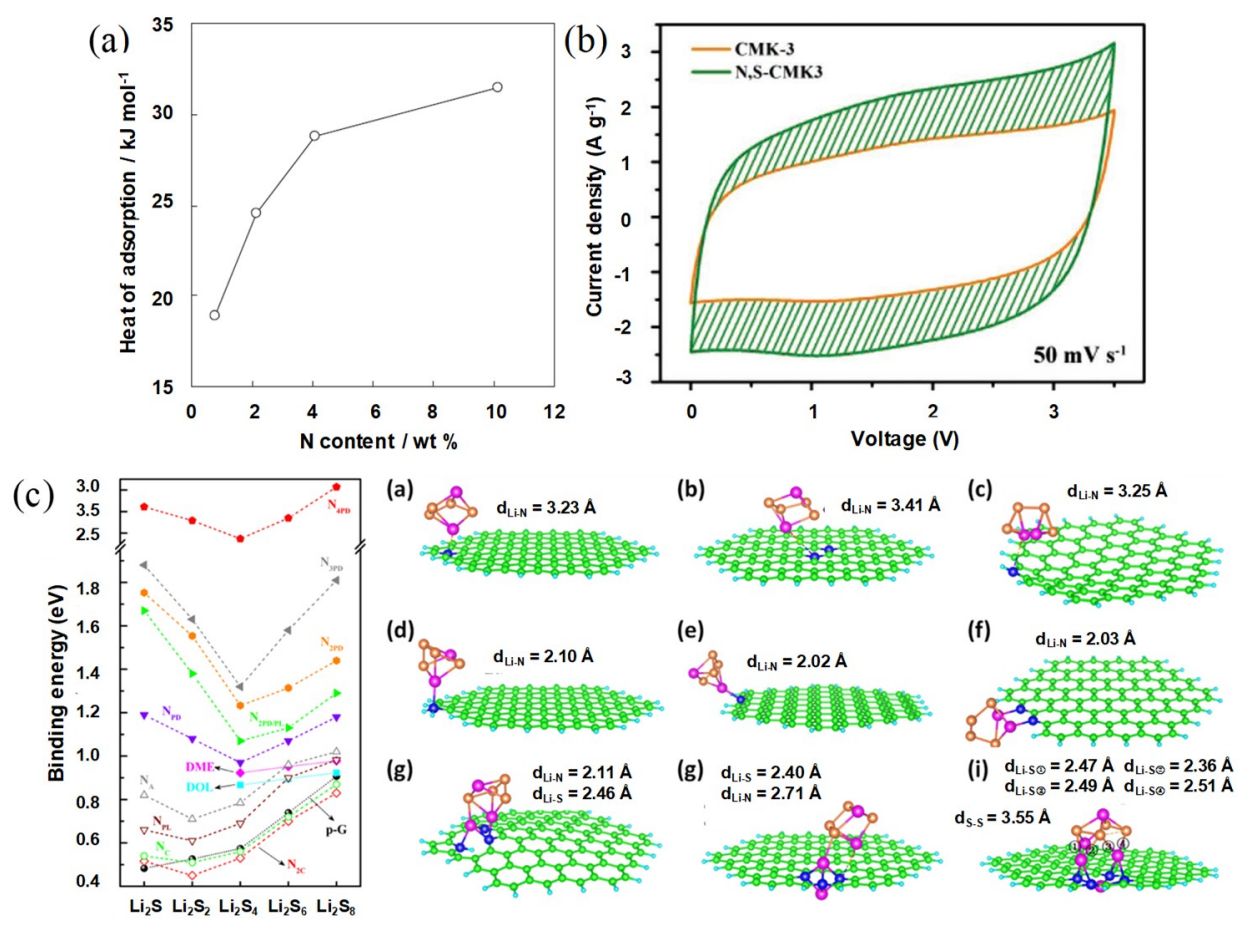

(d)

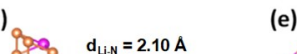

(e)

(f) $d_{\mathrm{LiN}}=2.03 \mathrm{~A}$
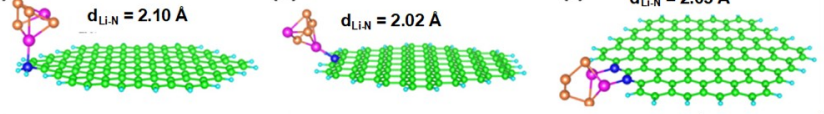

(g)
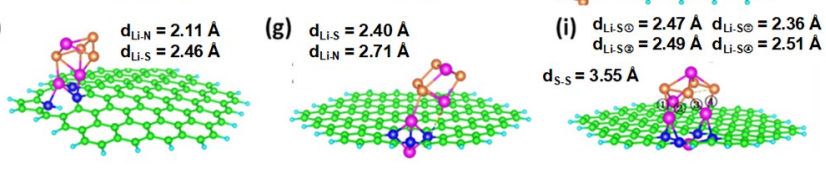

Figure 7. (a) Increase of the heat of $\mathrm{CO}_{2}$ adsorption at a surface coverage of $\sim 0.6 \mathrm{mmol} / \mathrm{g}$ with the increase of the nitrogen content of polypyrrole-based porous carbons [24]. (b) Cyclic voltammograms of ordered mesoporous CMK-3 and heteroatom-doped CMK-3 carbon electrodes in ionic liquid-based supercapacitors showing that heteroatoms enhance the energy storage [130]. (c) Calculated binding energies between lithium polysulfides and $\mathrm{N}$-doped graphenes with different doping configurations as well as optimized molecular structures of $\mathrm{Li}_{2} \mathrm{~S}_{4}$ on $\mathrm{N}$-doped graphenes [133]. (a) adapted from [24], with permission from Wiley, 2011; (b) adapted from [130], with permission from Wiley, 2018; (c) reproduced from [133], with permission from Elsevier, 2016.

To make full use of any chemical functionality on the internal surface area of NPCMs, these structure motives have to be fully accessible for the reactive guest species, that is, the pores have to be large enough to allow for their access into the entire volume. Just as by chemical functionality, the NPCM-guest interactions can also be influenced by the pore size. In this case, the strength of the interaction is usually lower, and is dominated by non-covalent (in most cases van der Waals) interactions. In general, the better the geometrical fit between NPCM pores and guest species, the stronger the interaction. Correlations between pore size and adsorption behavior have been widely researched in many fields such as selective gas capture [75], gas storage [65,140], ion adsorption [141,142], protein adsorption [126], and others. In simple words, a hand that is too large to hold an object cannot hold it strong enough, while a hand that is too small cannot hold it at all. 
This sounds to be very logical and is generally accepted, but there is a hidden conclusion that can be drawn: the pore size distribution of the NPCM has to be as well defined as possible to enable precise control over the strength of interaction, and, in ideal cases, even size exclusion effects (gas or ion "sieving") could be realized. In summary, the introduction of chemical functionality can be seen as the "stronger" regulation screw (higher interaction enthalpies are possible), whereas the pore size tailoring is the "finer" one (usually the interaction enthalpies are smaller but in theory continuously adjustable).

A very strong interaction between NPCM and guest species due to matching chemical binding and pore size is, in many cases, beneficial. However, the stronger the interaction, the slower the mass transfer within the bulk volume of the material, as guest species will mainly occupy the outer surface of the NPCM particles. This is not surprising, as a quite similar effect is widely known from the field of narrow pore zeolites. Highly-functionalized polar carbon materials with pore sizes in the range of the guest species can indeed have mass transport and adsorption properties comparable to zeolites [88]. Just like for zeolites, there seem to be two obvious ways to enhance accessibility of the internal surface of such materials. Both of them aim to keep the transport pathways through the areas with smaller pores as short as possible, and thus, make sure that more than only the external surface of the NPCM particles is used for the desired process. The first one is to decrease at least one particle dimension of the materials down to the nm-scale, that is, shape the NPCMs as thin films $[143,144]$, nanofibers $[145,146]$, or nanoparticles $[43,70]$. The second way is to introduce hierarchical porosity $[28,48]$. As mentioned above, hierarchically porous materials contain two pore systems of clearly distinguishable size which are in direct connection with each other. Mesopores will not enhance mass transport in a network of micropores if they are not connected, and single mesopores are surrounded by micropores. On the other side, even well-connected mesopores are useless if the micropores are not in their direct neighborhood. NPCMs with hierarchical pore architecture have proven able to overcome many transport limitations that are potentially present in materials with only narrow pores. However, some drawbacks of this method should also not be overlooked; the first is that a material with larger transport pores will always have a lower bulk density. This, in turn, will decrease the volumetric efficiency which is crucial in many applications. For example, excessive meso- and macropore volume in supercapacitor or battery electrodes brings volume that has to be filled with electrolyte but which does not necessarily contribute to energy storage capacity. In some cases, already the presence of a certain amount of larger micropores (i.e., the distribution of the pore size as such) will lead to sufficiently fast mass transfer throughout the bulk of the material. This, however, will decrease the strength of interaction. The questions of whether a truly hierarchical pore system is really needed, and what size, volume, and geometry of transport pores are required, have to be answered separately from application to application-depending on the conditions and the guest species. In some cases, the presence of a non-ideal hierarchical porosity can even be a disadvantage [147].

\subsection{Where Will the Field Go?}

From our point of view, three major fields of development can be foreseen for the field of NPCMs in energy and environmental applications. Presumably, all of them will contribute to a future more sustainable energy fabrication, energy storage, energy conversion, and to performance enhancements in other energy and environmentally relevant fields.

(i) From the synthetic perspective, really sustainable synthetic protocols have to be developed towards NPCM materials to make them even more attractive for large-scale use. So far, microporous activated carbons are the NPCM materials with by far the highest industrial production volume. Even though their production process suffers from often limited atomic efficiency, they will likely remain the class of NPCMs with the highest commercial relevance. From another perspective, it can be foreseen that mesoporous materials will play a more important role in the future, especially in catalysis and energy storage. A sustainable and scalable route for their production is yet to be developed. Since mesopores can appear over a much broader size range and with different shapes compared to micropores, this will presumably not be done with one process alone. 
Regarding the introduction of particular atomic structure motives into NPCMs, it is our belief that the molecular design of NPCMs is a more straightforward way to achieve homogeneous functionalization at high density in comparison to post-synthesis treatments. By using molecular precursors, a predefined condensation/carbonization pathway can be induced. In contrast, post-synthetic functionalization agents will come into contact with functional groups of different reactivity, and thus, functional sites with different properties will be introduced.

(ii) It has already been mentioned that carbon materials come with the advantage that their intrinsic properties can be precisely adjusted to suit a wide range of applications. However, in many applications there are multiple requirements for the materials. For example, in electrochemical energy management applications, specific adsorption sites for electrolyte species are often needed in the electrode material in combination with high electronic conductivity. This often leads to complementary requirements on the properties of the carbons. For that reason, we predict a more important role of carbon-based composite materials (and, in particular, of carbon-carbon composite materials) in the near future. If two carbon-based materials with different functionalities are combined in the right way, then each of them can contribute to a process with its individual advantages. For example, a relatively graphitic material with large pores can serve as an electrically conductive or mechanically stable backbone, while a layer of micro- or mesoporous heteroatom-rich carbon can ensure sufficiently strong interaction with a guest species.

(iii) In many energy and environmental applications, the interaction between carbon surface and surrounding species are still rarely understood. On the one side, this is related to the lack of molecular-level understanding due to the difficulty of modeling a realistic heterogeneous NPCM structure. On the other side, experimental studies about the fundamental mechanisms of surface and transport phenomena in carbon pores are still rare. However, only with such studies can a profound understanding of structure-performance relationships be achieved and novel mechanisms be explored. Based on such knowledge, a targeted enhancement of carbon materials and devices for future energy storage can be achieved. In our view, it is important not only that such studies are carried out at all, but also that they are performed with model materials with an atomic construction and a pore structure that is as well defined as possible. From this perspective, it is not surprising that carbide-derived carbons have played a major role in this field in recent years. If the aim of the researchers is the synthesis of really well-defined materials on a lab scale, then the synthesis does not necessarily have to be scalable. We still see much room for improvement in the field of such fundamental studies from both the materials side and from the viewpoint of measurement technology.

Finally, we are sure that there is possibly even more room for improvement by matching intelligent device design with advanced NPCMs than with one of them alone. Materials scientists often tend to apply their "standard device" for testing the performance of their newly synthesized materials, and sometimes ignore that the design of their devices is very far away from the real application. One obvious example from the field of supercapacitors is the very high number of publications reporting record-high capacities of NPCMs in $\mathrm{KOH}$ - or $\mathrm{H}_{2} \mathrm{SO}_{4}$-based aqueous electrolytes in 3-electrode configuration. In some cases, such data is neither meaningful for the future improvement of supercapacitors, nor are the numbers derived from them really useful to evaluate the performance of an NPCM. Li-S battery testing at very low sulfur mass and surface loading in the cathode and with large excesses of electrolyte is also not very meaningful, and the gas adsorption capacity at high pressures is not a crucial parameter to evaluate a material as a selective gas adsorbent. On the other side, engineers often use NPCMs and other materials as kind of a "black box", and tend to overlook the possible enhancements for their applications that can be achieved by using more suitable materials. In the future, materials scientists, chemists, physicists, and engineers should move closer together to achieve maximal possible synergy. 


\section{Special Issue of "C" on Functional Nanoporous Carbon-Based Materials}

Nanoporous carbon-based materials surely play and will play an ever-increasing role in energy and environmentally relevant applications. The works published in this special issue of C-Journal of Carbon Research are dealing with some of the aforementioned aspects of functional nanoporous carbon-based materials.

In two contributions, Schönherr et al. report novel insights into Boehm titration, which is one of the oldest characterization techniques for carbon surfaces. In the first article, practical aspects for achieving a high precision in the quantification of oxygen-containing surface groups in a short time are discussed [148]. In the second paper, the accuracy and limiting factors of Boehm titration for the quantification of oxygen-containing surface groups are evaluated in comparison to other established characterization techniques such as elemental analysis, temperature programmed desorption, and X-ray photoelectron spectroscopy [149].

In a work which is rather focused on synthetic aspects, Borchardt and co-workers report mechanochemistry as a promising alternative for the surface functionalization of carbon black with nitrogen- and oxygen-containing groups at room temperature by simply ball milling the carbon in ammonia solution. With the absence of harmful chemicals and conditions, the needlessness of complex and expensive synthesis setup, as well as low energy requirements, it is indeed a sustainable method for carbon functionalization [150].

Xing et al. present a novel synthesis strategy towards cobalt nanoparticles embedded into nitrogen-doped hollow carbon spheres. The nitrogen content is controllable by the synthesis temperature, and the resulting materials are applied as electrocatalysts in the oxygen reduction reaction (ORR). The remarkable catalytic properties are ascribed to the synergistic effect of $\mathrm{N}$-containing moieties, Co- $\mathrm{N}_{x}$ species, and Co nanoparticles, which significantly increase the density of active sites and promote charge transfer during the ORR process [151].

Seredych et al. contribute a work in which they investigate the adsorption of bovine serum albumin — the most abundant blood plasma protein—on carbon materials with different textural properties and different surface chemistries. Important insights into relationships between the carbon materials' properties and the adsorption efficiency are obtained, which is helpful to get an understanding of the structure-performance relationships of porous carbon materials in protein adsorption. The latter plays a very important role in biotechnology and biomolecular engineering, and it is one of the main factors determining bio- and hemo-compatibility of biomedical materials in medical applications, such as blood purification and wound healing [152].

The one-pot synthesis of carbon-sulfur composite materials and their use in Li-S battery cathodes is reported by Giebeler and co-workers. The simple chemical reduction of graphene oxide by a solution-based method leads to graphene networks that could be simply impregnated with sulfur nanoparticles from different precursors through a careful manipulation of $\mathrm{pH}$ of the chemical environment. It is found that sulfur nanoparticles derived from the acidification of sodium thiosulfate with chemically-reduced graphene oxide demonstrate favorable electrochemical behavior [153].

We sincerely hope that this collection of articles, written by leading experts in the field, as well as the present editorial perspective, may inspire readers for their future research on functional nanoporous carbon-based materials for energy and environmental applications.

Author Contributions: M.O. and R.W. wrote the paper.

Funding: The authors thank the Germany Chemical Industry Fund (Fonds der Chemischen Industrie) for financial support by a Liebig Stipendium.

Acknowledgments: The authors thank Markus Antonietti (Max Planck Institute of Colloids and Interfaces) for his continuing support and supervision. We also thank Lars Borchardt (TU Dresden for helpful discussions.

Conflicts of Interest: The authors declare no conflict of interest. 


\section{References}

1. Roston, E. The Carbon Age: How Life's Core Element Has Become Civilization's Greatest Threat; Walker \& Company: New York, NY, USA, 2008.

2. Rosa, R.N. The role of synthetic fuels for a carbon neutral economy. C 2017, 3, 11. [CrossRef]

3. Andreoli, E. Materials and processes for carbon dioxide capture and utilisation. $C$ 2017, 3, 16. [CrossRef]

4. Gogotsi, Y.; Presser, V. (Eds.) Carbon Nanomaterials; CRC Press: Boca Raton, FL, USA, 2014.

5. Tascón, J.M.D. (Ed.) Novel Carbon Adsorbents; Elsevier: Oxford, UK, 2012; ISBN 9780080977454.

6. Serp, P.; Figueiredo, J.L. (Eds.) Carbon Materials for Catalysis; John Wiley \& Sons, Inc.: Hoboken, NJ, USA, 2009; ISBN 978-0-470-17885-0.

7. Krüger, A. (Ed.) Carbon Materials and Nanotechnology; Wiley-VCH: Weinheim, Germany, 2010.

8. Feng, X. (Ed.) Nanocarbons for Advanced Energy Storage; Wiley-VCH: Weinheim, Germany, 2015.

9. Hong, G.; Diao, S.; Antaris, A.L.; Dai, H. Carbon nanomaterials for biological imaging and nanomedicinal therapy. Chem. Rev. 2015, 115, 10816-10906. [CrossRef] [PubMed]

10. Dai, L.; Chang, D.W.; Baek, J.B.; Lu, W. Carbon nanomaterials for advanced energy conversion and storage. Small 2012, 8, 1130-1166. [CrossRef] [PubMed]

11. Llobet, E. Gas sensors using carbon nanomaterials: A review. Sens. Actuators B Chem. 2013, 179, 32-45. [CrossRef]

12. Lee, J.; Kim, J.; Hyeon, T. Recent progress in the synthesis of porous carbon materials. Adv. Mater. 2006, 18, 2073-2094. [CrossRef]

13. Xia, Y.; Yang, Z.; Mokaya, R. Templated nanoscale porous carbons. Nanoscale 2010, 2, 639-659. [CrossRef] [PubMed]

14. Palmer, J.C.; Llobet, A.; Yeon, S.H.; Fischer, J.E.; Shi, Y.; Gogotsi, Y.; Gubbins, K.E. Modeling the structural evolution of carbide-derived carbons using quenched molecular dynamics. Carbon 2010, 48, 1116-1123. [CrossRef]

15. Thomas, A.; Kuhn, P.; Weber, J.; Titirici, M.M.; Antonietti, M. Porous polymers: Enabling solutions for energy applications. Macromol. Rapid Commun. 2009, 30, 221-236. [CrossRef] [PubMed]

16. Chaoui, N.; Trunk, M.; Dawson, R.; Schmidt, J.; Thomas, A. Trends and challenges for microporous polymers. Chem. Soc. Rev. 2017, 46, 3302-3321. [CrossRef] [PubMed]

17. Thomas, A. Functional materials: From hard to soft porous frameworks. Angew. Chem. Int. Ed. 2010, 49, 8328-8344. [CrossRef] [PubMed]

18. Schneemann, A.; Bon, V.; Schwedler, I.; Senkovska, I.; Kaskel, S.; Fischer, R.A. Flexible metal-organic frameworks. Chem. Soc. Rev. 2014, 43, 6062-6096. [CrossRef] [PubMed]

19. Li, B.; Wen, H.M.; Cui, Y.; Zhou, W.; Qian, G.; Chen, B. Emerging multifunctional metal-organic framework materials. Adv. Mater. 2016, 28, 8819-8860. [CrossRef] [PubMed]

20. Sakaushi, K.; Antonietti, M. Carbon- and nitrogen-based porous solids: A recently emerging class of materials. Bull. Chem. Soc. Jpn. 2015, 88, 386-398. [CrossRef]

21. Stein, A.; Wang, Z.; Fierke, M.A. Functionalization of porous carbon materials with designed pore architecture. Adv. Mater. 2009, 21, 265-293. [CrossRef]

22. Paraknowitsch, J.P.; Thomas, A. Doping carbons beyond nitrogen: An overview of advanced heteroatom doped carbons with boron, sulphur and phosphorus for energy applications. Energy Environ. Sci. 2013, 6, 2839-2855. [CrossRef]

23. Inagaki, M.; Toyoda, M.; Soneda, Y.; Morishita, T. Nitrogen-doped carbon materials. Carbon 2018, 132, 104-140. [CrossRef]

24. Sevilla, M.; Valle-Vigón, P.; Fuertes, A.B. N-doped polypyrrole-based porous carbons for $\mathrm{CO}_{2}$ capture. Adv. Funct. Mater. 2011, 21, 2781-2787. [CrossRef]

25. Lopez-Salas, N.; del Monte, F.; Tamayo, A.; Fierro, J.L.; De Lacey, A.L.; Ferrer, M.L.; Gutierrez, M.C. Sulfur-doped carbons prepared from eutectic mixtures containing hydroxymethylthiophene as metal-free oxygen reduction catalysts. ChemSusChem 2014, 7, 3347-3355. [CrossRef] [PubMed]

26. Thommes, M.; Kaneko, K.; Neimark, A.V.; Olivier, J.P.; Rodriguez-Reinoso, F.; Rouquerol, J.; Sing, K.S.W. Physisorption of gases, with special reference to the evaluation of surface area and pore size distribution (IUPAC Technical Report). Pure Appl. Chem. 2015, 87, 1051-1069. [CrossRef] 
27. Fang, B.; Kim, J.H.; Kim, M.-S.; Yu, J.-S. Hierarchical nanostructured carbons with meso-macroporosity: Design, characterization, and applications. Acc. Chem. Res. 2013, 46, 1397-1406. [CrossRef] [PubMed]

28. Oschatz, M.; Borchardt, L.; Thommes, M.; Cychosz, K.A.; Senkovska, I.; Klein, N.; Frind, R.; Leistner, M.; Presser, V.; Gogotsi, Y.; et al. Carbide-derived carbon monoliths with hierarchical pore architectures. Angew. Chem. Int. Ed. 2012, 51, 7577-7580. [CrossRef] [PubMed]

29. Schwieger, W.; Machoke, A.G.; Weissenberger, T.; Inayat, A.; Selvam, T.; Klumpp, M.; Inayat, A. Hierarchy concepts: Classification and preparation strategies for zeolite containing materials with hierarchical porosity. Chem. Soc. Rev. 2016, 45, 3353-3376. [CrossRef] [PubMed]

30. Zhao, Y.; Liu, X.; Han, Y. Microporous carbonaceous adsorbents for $\mathrm{CO}_{2}$ separation via selective adsorption. RSC Adv. 2015, 5, 30310-30330. [CrossRef]

31. Yang, Z.; Yao, Z.; Li, G.; Fang, G.; Nie, H.; Liu, Z.; Zhou, X.; Chen, X.; Huang, S. Sulfur-doped graphene as an efficient metal-free cathode catalyst for oxygen reduction. ACS Nano 2012, 6, 205-211. [CrossRef] [PubMed]

32. Hu, B.; Wang, K.; Wu, L.; Yu, S.H.; Antonietti, M.; Titirici, M.M. Engineering carbon materials from the hydrothermal carbonization process of biomass. Adv. Mater. 2010, 22, 813-828. [CrossRef] [PubMed]

33. Titirici, M.M.; Antonietti, M. Chemistry and materials options of sustainable carbon materials made by hydrothermal carbonization. Chem. Soc. Rev. 2010, 39, 103-116. [CrossRef] [PubMed]

34. Sevilla, M.; Yu, L.; Ania, C.O.; Titirici, M.-M. Supercapacitive behavior of two glucose-derived microporous carbons: Direct pyrolysis versus hydrothermal carbonization. ChemElectroChem 2014, 1, 2138-2145. [CrossRef]

35. Grätz, S.; Beyer, D.; Tkachova, V.; Hellmann, S.; Berger, R.; Feng, X.; Borchardt, L. The mechanochemical scholl reaction-A solvent-free and versatile graphitization tool. Chem. Commun. 2018, 54, 5307-5310.

36. Schneidermann, C.; Jackel, N.; Oswald, S.; Giebeler, L.; Presser, V.; Borchardt, L. Solvent-free mechanochemical synthesis of nitrogen-doped nanoporous carbon for electrochemical energy storage. ChemSusChem 2017, 10, 2416-2424. [CrossRef] [PubMed]

37. Casco, M.E.; Badaczewski, F.; Grätz, S.; Tolosa, A.; Presser, V.; Smarsly, B.M.; Borchardt, L. Mechanochemical synthesis of porous carbon at room temperature with a highly ordered $\mathrm{sp}^{2}$ microstructure. Carbon 2018, 139, 325-333. [CrossRef]

38. Borchardt, L.; Zhu, Q.-L.; Casco, M.E.; Berger, R.; Zhuang, X.; Kaskel, S.; Feng, X.; Xu, Q. Toward a molecular design of porous carbon materials. Mater. Today 2017, 20, 592-610. [CrossRef]

39. Fuchs, I.; Fechler, N.; Antonietti, M.; Mastai, Y. Enantioselective nanoporous carbon based on chiral ionic liquids. Angew. Chem. Int. Ed. 2016, 55, 408-412. [CrossRef] [PubMed]

40. Fechler, N.; Zussblatt, N.P.; Rothe, R.; Schlogl, R.; Willinger, M.G.; Chmelka, B.F.; Antonietti, M. Eutectic syntheses of graphitic carbon with high pyrazinic nitrogen content. Adv. Mater. 2016, 28, 1287-1294. [CrossRef] [PubMed]

41. Roberts, A.D.; Li, X.; Zhang, H. Porous carbon spheres and monoliths: Morphology control, pore size tuning and their applications as li-ion battery anode materials. Chem. Soc. Rev. 2014, 43, 4341-4356. [CrossRef] [PubMed]

42. Hu, Y.S.; Adelhelm, P.; Smarsly, B.M.; Hore, S.; Antonietti, M.; Maier, J. Synthesis of hierarchically porous carbon monoliths with highly ordered microstructure and their application in rechargeable lithium batteries with high-rate capability. Adv. Funct. Mater. 2007, 17, 1873-1878. [CrossRef]

43. Oschatz, M.; Zeiger, M.; Jäckel, N.; Strubel, P.; Borchardt, L.; Reinhold, R.; Nickel, W.; Eckert, J.; Presser, V.; Kaskel, S. Emulsion soft templating of carbide-derived carbon nanospheres with controllable porosity for capacitive electrochemical energy storage. J. Mater. Chem. A 2015, 3, 17983-17990. [CrossRef]

44. Ryoo, R.; Joo, S.H.; Kruk, M.; Jaroniec, M. Ordered mesoporous carbons. Adv. Mater. 2001, 13, 677-681. [CrossRef]

45. Chuenchom, L.; Kraehnert, R.; Smarsly, B.M. Recent progress in soft-templating of porous carbon materials. Soft Matter 2012, 8, 10801-10812. [CrossRef]

46. Oschatz, M.; Kockrick, E.; Rose, M.; Borchardt, L.; Klein, N.; Senkovska, I.; Freudenberg, T.; Korenblit, Y.; Yushin, G.; Kaskel, S. A cubic ordered, mesoporous carbide-derived carbon for gas and energy storage applications. Carbon 2010, 48, 3987-3992. [CrossRef]

47. Oschatz, M.; Nickel, W.; Thommes, M.; Cychosz, K.A.; Leistner, M.; Adam, M.; Mondin, G.; Strubel, P.; Borchardt, L.; Kaskel, S. Evolution of porosity in carbide-derived carbon aerogels. J. Mater. Chem. A 2014, 2, 18472-18479. [CrossRef] 
48. Oschatz, M.; Boukhalfa, S.; Nickel, W.; Hofmann, J.P.; Fischer, C.; Yushin, G.; Kaskel, S. Carbide-derived carbon aerogels with tunable pore structure as versatile electrode material in high power supercapacitors. Carbon 2017, 113, 283-291. [CrossRef]

49. Oschatz, M.; Borchardt, L.; Pinkert, K.; Thieme, S.; Lohe, M.R.; Hoffmann, C.; Benusch, M.; Wisser, F.M.; Ziegler, C.; Giebeler, L.; et al. Hierarchical carbide-derived carbon foams with advanced mesostructure as a versatile electrochemical energy-storage material. Adv. Energy Mater. 2014, 4, 1300645. [CrossRef]

50. Lee, J.; Sohn, K.; Hyeon, T. Fabrication of novel mesocellular carbon foams with uniform ultralarge mesopores. J. Am. Chem. Soc. 2001, 123, 5146-5147. [CrossRef] [PubMed]

51. Erythropel, H.C.; Zimmerman, J.B.; de Winter, T.M.; Petitjean, L.; Melnikov, F.; Lam, C.H.; Lounsbury, A.W.; Mellor, K.E.; Janković, N.Z.; Tu, Q.; et al. The green chemistree: 20 years after taking root with the 12 principles. Green Chem. 2018, 20, 1929-1961. [CrossRef]

52. Fic, K.; Platek, A.; Piwek, J.; Frackowiak, E. Sustainable materials for electrochemical capacitors. Mater. Today 2018, 21, 437-454. [CrossRef]

53. Lim, S.; Suh, K.; Kim, Y.; Yoon, M.; Park, H.; Dybtsev, D.N.; Kim, K. Porous carbon materials with a controllable surface area synthesized from metal-organic frameworks. Chem. Commun. 2012, 48, 7447-7449. [CrossRef] [PubMed]

54. Jiang, H.L.; Liu, B.; Lan, Y.Q.; Kuratani, K.; Akita, T.; Shioyama, H.; Zong, F.; Xu, Q. From metal-organic framework to nanoporous carbon: Toward a very high surface area and hydrogen uptake. J. Am. Chem. Soc. 2011, 133, 11854-11857. [CrossRef] [PubMed]

55. Yang, L.; Zeng, X.; Wang, W.; Cao, D. Recent progress in MOF-derived, heteroatom-doped porous carbons as highly efficient electrocatalysts for oxygen reduction reaction in fuel cells. Adv. Funct. Mater. 2018, 28, 1704537. [CrossRef]

56. Tang, J.; Salunkhe, R.R.; Liu, J.; Torad, N.L.; Imura, M.; Furukawa, S.; Yamauchi, Y. Thermal conversion of core-shell metal-organic frameworks: A new method for selectively functionalized nanoporous hybrid carbon. J. Am. Chem. Soc. 2015, 137, 1572-1580. [CrossRef] [PubMed]

57. Oschatz, M.; Krause, S.; Krans, N.A.; Hernandez Mejia, C.; Kaskel, S.; de Jong, K.P. Influence of precursor porosity on sodium and sulfur promoted iron/carbon fischer-tropsch catalysts derived from metal-organic frameworks. Chem. Commun. 2017, 53, 10204-10207. [CrossRef] [PubMed]

58. Wang, C.; Kaneti, Y.V.; Bando, Y.; Lin, J.; Liu, C.; Li, J.; Yamauchi, Y. Metal-organic framework-derived one-dimensional porous or hollow carbon-based nanofibers for energy storage and conversion. Mater. Horiz. 2018, 5, 394-407. [CrossRef]

59. Hao, G.P.; Li, W.C.; Qian, D.; Wang, G.H.; Zhang, W.P.; Zhang, T.; Wang, A.Q.; Schuth, F.; Bongard, H.J.; $\mathrm{Lu}$, A.H. Structurally designed synthesis of mechanically stable poly (benzoxazine-co-resol)-based porous carbon monoliths and their application as high-performance $\mathrm{CO}_{2}$ capture sorbents. J. Am. Chem. Soc. 2011, 133, 11378-11388. [CrossRef] [PubMed]

60. Presser, V.; Heon, M.; Gogotsi, Y. Carbide-derived carbons-From porous networks to nanotubes and graphene. Adv. Funct. Mater. 2011, 21, 810-833. [CrossRef]

61. Gogotsi, Y.; Nikitin, A.; Ye, H.; Zhou, W.; Fischer, J.E.; Yi, B.; Foley, H.C.; Barsoum, M.W. Nanoporous carbide-derived carbon with tunable pore size. Nat. Mater. 2003, 2, 591-594. [CrossRef] [PubMed]

62. Jänes, A.; Thomberg, T.; Kurig, H.; Lust, E. Nanoscale fine-tuning of porosity of carbide-derived carbon prepared from molybdenum carbide. Carbon 2009, 47, 23-29. [CrossRef]

63. Dash, R.; Chmiola, J.; Yushin, G.; Gogotsi, Y.; Laudisio, G.; Singer, J.; Fischer, J.; Kucheyev, S. Titanium carbide derived nanoporous carbon for energy-related applications. Carbon 2006, 44, 2489-2497. [CrossRef]

64. Futamura, R.; Iiyama, T.; Takasaki, Y.; Gogotsi, Y.; Biggs, M.J.; Salanne, M.; Segalini, J.; Simon, P.; Kaneko, K. Partial breaking of the coulombic ordering of ionic liquids confined in carbon nanopores. Nat. Mater. 2017, 16, 1225-1232. [CrossRef] [PubMed]

65. Presser, V.; McDonough, J.; Yeon, S.-H.; Gogotsi, Y. Effect of pore size on carbon dioxide sorption by carbide derived carbon. Energy Environ. Sci. 2011, 4, 3059-3066. [CrossRef]

66. Silvestre-Albero, A.; Rico-Francés, S.; Rodríguez-Reinoso, F.; Kern, A.M.; Klumpp, M.; Etzold, B.J.M.; Silvestre-Albero, J. High selectivity of TiC-CDC for $\mathrm{CO}_{2} / \mathrm{N}_{2}$ separation. Carbon 2013, 59, 221-228. [CrossRef] 
67. Oschatz, M.; Hoffmann, H.C.; Pallmann, J.; Schaber, J.; Borchardt, L.; Nickel, W.; Senkovska, I.; Rico-Francés, S.; Silvestre-Albero, J.; Kaskel, S.; et al. Structural characterization of micro- and mesoporous carbon materials using in situ high pressure ${ }^{129}$ Xe nmr spectroscopy. Chem. Mater. 2014, 26, 3280-3288. [CrossRef]

68. Porada, S.; Borchardt, L.; Oschatz, M.; Bryjak, M.; Atchison, J.S.; Keesman, K.J.; Kaskel, S.; Biesheuvel, P.M.; Presser, V. Direct prediction of the desalination performance of porous carbon electrodes for capacitive deionization. Energy Environ. Sci. 2013, 6, 3700-3712. [CrossRef]

69. Zera, E.; Nickel, W.; Hao, G.P.; Vanzetti, L.; Kaskel, S.; Sorarù, G.D. Nitrogen doped carbide derived carbon aerogels by chlorine etching of a sicn aerogel. J. Mater. Chem. A 2016, 4, 4525-4533. [CrossRef]

70. Pérez, C.R.; Yeon, S.-H.; Ségalini, J.; Presser, V.; Taberna, P.-L.; Simon, P.; Gogotsi, Y. Structure and electrochemical performance of carbide-derived carbon nanopowders. Adv. Funct. Mater. 2013, 23, 1081-1089. [CrossRef]

71. Sevilla, M.; Mokaya, R. Energy storage applications of activated carbons: Supercapacitors and hydrogen storage. Energy Environ. Sci. 2014, 7, 1250-1280. [CrossRef]

72. Oschatz, M.; Borchardt, L.; Senkovska, I.; Klein, N.; Leistner, M.; Kaskel, S. Carbon dioxide activated carbide-derived carbon monoliths as high performance adsorbents. Carbon 2013, 56, 139-145. [CrossRef]

73. Osswald, S.; Portet, C.; Gogotsi, Y.; Laudisio, G.; Singer, J.P.; Fischer, J.E.; Sokolov, V.V.; Kukushkina, J.A.; Kravchik, A.E. Porosity control in nanoporous carbide-derived carbon by oxidation in air and carbon dioxide. J. Solid State Chem. 2009, 182, 1733-1741. [CrossRef]

74. Salinas-Torres, D.; Lozano-Castelló, D.; Titirici, M.M.; Zhao, L.; Yu, L.; Morallón, E.; Cazorla-Amoros, D. Electrochemical behaviour of activated carbons obtained via hydrothermal carbonization. J. Mater. Chem. A 2015, 3, 15558-15567. [CrossRef]

75. Wang, J.; Heerwig, A.; Lohe, M.R.; Oschatz, M.; Borchardt, L.; Kaskel, S. Fungi-based porous carbons for $\mathrm{CO}_{2}$ adsorption and separation. J. Mater. Chem. 2012, 22, 13911-13913. [CrossRef]

76. Lu, A.H.; Schüth, F. Nanocasting: A versatile strategy for creating nanostructured porous materials. Adv. Mater. 2006, 18, 1793-1805. [CrossRef]

77. Yang, H.; Zhao, D. Synthesis of replica mesostructures by the nanocasting strategy. J. Mater. Chem. 2005, 15, 1217-1231. [CrossRef]

78. Meng, Y.; Gu, D.; Zhang, F.; Shi, Y.; Yang, H.; Li, Z.; Yu, C.; Tu, B.; Zhao, D. Ordered mesoporous polymers and homologous carbon frameworks: Amphiphilic surfactant templating and direct transformation. Angew. Chem. Int. Ed. 2005, 44, 7053-7059. [CrossRef] [PubMed]

79. Oschatz, M.; Lee, J.T.; Kim, H.; Nickel, W.; Borchardt, L.; Cho, W.I.; Ziegler, C.; Kaskel, S.; Yushin, G. Microand mesoporous carbide-derived carbon prepared by a sacrificial template method in high performance lithium sulfur battery cathodes. J. Mater. Chem. A 2014, 2, 17649-17654. [CrossRef]

80. Yan, R.; Heil, T.; Presser, V.; Walczak, R.; Antonietti, M.; Oschatz, M. Ordered mesoporous carbons with high micropore content and tunable structure prepared by combined hard and salt templating as electrode materials in electric double-layer capacitors. Adv. Sustain. Syst. 2018, 2, 1700128. [CrossRef]

81. Borchardt, L.; Oschatz, M.; Lohe, M.; Presser, V.; Gogotsi, Y.; Kaskel, S. Ordered mesoporous carbide-derived carbons prepared by soft templating. Carbon 2012, 50, 3987-3994. [CrossRef]

82. Ma, T.Y.; Liu, L.; Yuan, Z.Y. Direct synthesis of ordered mesoporous carbons. Chem. Soc. Rev. 2013, 42, 3977-4003. [CrossRef] [PubMed]

83. Ryoo, R.; Joo, S.H.; Jun, S. Synthesis of highly ordered carbon molecular sieves via template-mediated structural transformation. J. Phys. Chem. B 1999, 103, 7743-7746. [CrossRef]

84. Fechler, N.; Fellinger, T.P.; Antonietti, M. "Salt templating": A simple and sustainable pathway toward highly porous functional carbons from ionic liquids. Adv. Mater. 2013, 25, 75-79. [CrossRef] [PubMed]

85. Yan, R.; Antonietti, M.; Oschatz, M. Toward the experimental understanding of the energy storage mechanism and ion dynamics in ionic liquid based supercapacitors. Adv. Energy Mater. 2018, 8, 1800026. [CrossRef]

86. Oschatz, M.; Boukhalfa, S.; Nickel, W.; Lee, J.T.; Klosz, S.; Borchardt, L.; Eychmüller, A.; Yushin, G.; Kaskel, S. Kroll-carbons based on silica and alumina templates as high-rate electrode materials in electrochemical double-layer capacitors. J. Mater. Chem. A 2014, 2, 5131-5139. [CrossRef]

87. Nickel, W.; Oschatz, M.; Rico-Frances, S.; Klosz, S.; Biemelt, T.; Mondin, G.; Eychmüller, A.; Silvestre-Albero, J.; Kaskel, S. Synthesis of ordered mesoporous carbon materials by dry etching. Chem. Eur. J. 2015, 21, 14753-14757. [CrossRef] [PubMed] 
88. Walczak, R.; Kurpil, B.; Savateev, A.; Heil, T.; Schmidt, J.; Qin, Q.; Antonietti, M.; Oschatz, M. Templateand metal-free synthesis of nitrogen-rich nanoporous "noble" carbon materials by direct pyrolysis of a preorganized hexaazatriphenylene precursor. Angew. Chem. Int. Ed. 2018, 57, 10765-10770. [CrossRef] [PubMed]

89. White, R.J.; Brun, N.; Budarin, V.L.; Clark, J.H.; Titirici, M.M. Always look on the "light" side of life: Sustainable carbon aerogels. ChemSusChem 2014, 7, 670-689. [CrossRef] [PubMed]

90. Lin, C.; Ritter, J.A. Carbonization and activation of sol-gel derived carbon xerogels. Carbon 2000, 38, 849-861. [CrossRef]

91. Oschatz, M.; Pré, P.; Dörfler, S.; Nickel, W.; Beaunier, P.; Rouzaud, J.-N.; Fischer, C.; Brunner, E.; Kaskel, S. Nanostructure characterization of carbide-derived carbons by morphological analysis of transmission electron microscopy images combined with physisorption and raman spectroscopy. Carbon 2016, 105, 314-322. [CrossRef]

92. Faber, K.; Badaczewski, F.; Oschatz, M.; Mondin, G.; Nickel, W.; Kaskel, S.; Smarsly, B.M. In-depth investigation of the carbon microstructure of silicon carbide-derived carbons by wide-angle x-ray scattering. J. Phys. Chem. C 2014, 118, 15705-15715. [CrossRef]

93. Mangarella, M.C.; Ewbank, J.L.; Dutzer, M.R.; Alamgir, F.M.; Walton, K.S. Synthesis of embedded iron nanoparticles in $\mathrm{Fe}_{3} \mathrm{C}$-derived carbons. Carbon 2014, 79, 74-84. [CrossRef]

94. Oschatz, M.; van Deelen, T.W.; Weber, J.L.; Lamme, W.S.; Wang, G.; Goderis, B.; Verkinderen, O.; Dugulan, A.I.; de Jong, K.P. Effects of calcination and activation conditions on ordered mesoporous carbon supported iron catalysts for production of lower olefins from synthesis gas. Catal. Sci. Technol. 2016, 6, 8464-8473. [CrossRef]

95. Antonietti, M.; Oschatz, M. The concept of "noble, heteroatom-doped carbons," their directed synthesis by electronic band control of carbonization, and applications in catalysis and energy materials. Adv. Mater. 2018, 30, 1706836. [CrossRef] [PubMed]

96. Li, W.; Fechler, N.; Bandosz, T.J. Chemically heterogeneous nitrogen sites of various reactivity in porous carbons provide high stability of $\mathrm{CO}_{2}$ electroreduction catalysts. Appl. Catal. B Environ. 2018, 234, 1-9. [CrossRef]

97. Ju, W.; Bagger, A.; Hao, G.P.; Varela, A.S.; Sinev, I.; Bon, V.; Roldan Cuenya, B.; Kaskel, S.; Rossmeisl, J.; Strasser, P. Understanding activity and selectivity of metal-nitrogen-doped carbon catalysts for electrochemical reduction of $\mathrm{CO}_{2}$. Nat. Commun. 2017, 8, 944. [CrossRef] [PubMed]

98. Oschatz, M.; Hofmann, J.P.; van Deelen, T.W.; Lamme, W.S.; Krans, N.A.; Hensen, E.J.; de Jong, K.P. Effects of the functionalization of the ordered mesoporous carbon support surface on iron catalysts for the fischer-tropsch synthesis of lower olefins. ChemCatChem 2017, 9, 620-628. [CrossRef] [PubMed]

99. Lama, S.M.G.; Schmidt, J.; Malik, A.; Walczak, R.; Silva, D.V.; Völkel, A.; Oschatz, M. Modification of salt-templated carbon surface chemistry for efficient oxidation of glucose with supported gold catalysts. ChemCatChem 2018, 10, 2458-2465. [CrossRef]

100. Qin, Q.; Heil, T.; Antonietti, M.; Oschatz, M. Single-site gold catalysts on hierarchical n-doped porous noble carbon for enhanced electrochemical reduction of nitrogen. Small Methods 2018, 1800202. [CrossRef]

101. Men, Y.; Siebenbürger, M.; Qiu, X.; Antonietti, M.; Yuan, J. Low fractions of ionic liquid or poly (ionic liquid) can activate polysaccharide biomass into shaped, flexible and fire-retardant porous carbons. J. Mater. Chem. A 2013, 1, 11887-11893. [CrossRef]

102. Nishihara, H.; Kyotani, T. Zeolite-templated carbons-three-dimensional microporous graphene frameworks. Chem. Commun. 2018, 54, 5648-5673. [CrossRef] [PubMed]

103. Péan, C.; Merlet, C.; Rotenberg, B.; Madden, P.A.; Taberna, P.-L.; Daffos, B.; Salanne, M.; Simon, P. On the dynamics of charging in nanoporous carbon-based supercapacitors. ACS Nano 2014, 8, 1576-1583. [CrossRef] [PubMed]

104. Merlet, C.; Rotenberg, B.; Madden, P.A.; Taberna, P.L.; Simon, P.; Gogotsi, Y.; Salanne, M. On the molecular origin of supercapacitance in nanoporous carbon electrodes. Nat. Mater. 2012, 11, 306-310. [CrossRef] [PubMed]

105. Merlet, C.; Pean, C.; Rotenberg, B.; Madden, P.A.; Daffos, B.; Taberna, P.L.; Simon, P.; Salanne, M. Highly confined ions store charge more efficiently in supercapacitors. Nat. Commun. 2013, 4, 2701. [CrossRef] [PubMed] 
106. Shim, Y.; Kim, H.J. Nanoporous carbon supercapacitors in an ionic liquid: A computer simulation study. ACS Nano 2010, 4, 2345-2355. [CrossRef] [PubMed]

107. Brunauer, S.; Emmett, P.H.; Teller, E. Adsorption of gases in multimolecular layers. J. Am. Chem. Soc. 1938, 60, 309-319. [CrossRef]

108. Barrett, E.P.; Joyner, L.G.; Halenda, P.P. The determination of pore volume and area distributions in porous substances. I. Computations from nitrogen isotherms. J. Am. Chem. Soc. 1951, 73, 373-380. [CrossRef]

109. Thommes, M. Physical adsorption characterization of nanoporous materials. Chem. Ing. Tech. 2010, 82, 1059-1073. [CrossRef]

110. Olivier, J.P. Improving the models used for calculating the size distribution of micropore volume of activated carbons from adsorption data. Carbon 1998, 36, 1469-1472. [CrossRef]

111. Jagiello, J.; Olivier, J.P. 2d-nldft adsorption models for carbon slit-shaped pores with surface energetical heterogeneity and geometrical corrugation. Carbon 2013, 55, 70-80. [CrossRef]

112. Neimark, A.V.; Lin, Y.; Ravikovitch, P.I.; Thommes, M. Quenched solid density functional theory and pore size analysis of micro-mesoporous carbons. Carbon 2009, 47, 1617-1628. [CrossRef]

113. Silvestre-Albero, J.; Silvestre-Albero, A.; Rodríguez-Reinoso, F.; Thommes, M. Physical characterization of activated carbons with narrow microporosity by nitrogen $(77.4 \mathrm{~K})$, carbon dioxide $(273 \mathrm{~K})$ and argon $(87.3 \mathrm{~K})$ adsorption in combination with immersion calorimetry. Carbon 2012, 50, 3128-3133. [CrossRef]

114. Osswald, S.; Chmiola, J.; Gogotsi, Y. Structural evolution of carbide-derived carbons upon vacuum annealing. Carbon 2012, 50, 4880-4886. [CrossRef]

115. Ferrari, A.C.; Robertson, J. Interpretation of Raman spectra of disordered and amorphous carbon. Phys. Rev. B. 2000, 61, 14095-14107. [CrossRef]

116. Bokobza, L.; Bruneel, J.-L.; Couzi, M. Raman spectra of carbon-based materials (from graphite to carbon black) and of some silicone composites. C 2015, 1, 77-94. [CrossRef]

117. Pré, P.; Huchet, G.; Jeulin, D.; Rouzaud, J.-N.; Sennour, M.; Thorel, A. A new approach to characterize the nanostructure of activated carbons from mathematical morphology applied to high resolution transmission electron microscopy images. Carbon 2013, 52, 239-258. [CrossRef]

118. He, L.; Weniger, F.; Neumann, H.; Beller, M. Synthesis, characterization, and application of metal nanoparticles supported on nitrogen-doped carbon: Catalysis beyond electrochemistry. Angew. Chem. Int. Ed. 2016, 55, 12582-12594. [CrossRef] [PubMed]

119. López-Salas, N.; Gutiérrez, M.C.; Ania, C.O.; Muñoz-Márquez, M.A.; Luisa Ferrer, M.; Monte, F.D. Nitrogen-doped carbons prepared from eutectic mixtures as metal-free oxygen reduction catalysts. J. Mater. Chem. A 2016, 4, 478-488. [CrossRef]

120. Su, D.S.; Perathoner, S.; Centi, G. Nanocarbons for the development of advanced catalysts. Chem. Rev. 2013, 113, 5782-5816. [CrossRef] [PubMed]

121. Navalon, S.; Dhakshinamoorthy, A.; Alvaro, M.; Antonietti, M.; Garcia, H. Active sites on graphene-based materials as metal-free catalysts. Chem. Soc. Rev. 2017, 46, 4501-4529. [CrossRef] [PubMed]

122. Oschatz, M.; Antonietti, M. A search for selectivity to enable $\mathrm{CO}_{2}$ capture with porous adsorbents. Energy Environ. Sci. 2018, 11, 57-70. [CrossRef]

123. Hirst, E.A.; Taylor, A.; Mokaya, R. A simple flash carbonization route for conversion of biomass to porous carbons with high $\mathrm{CO}_{2}$ storage capacity. J. Mater. Chem. A 2018, 6, 12393-12403. [CrossRef]

124. Hao, G.-P.; Li, W.-C.; Wang, S.; Zhang, S.; Lu, A.-H. Tubular structured ordered mesoporous carbon as an efficient sorbent for the removal of dyes from aqueous solutions. Carbon 2010, 48, 3330-3339. [CrossRef]

125. Fischer, C.; Oschatz, M.; Nickel, W.; Leistenschneider, D.; Kaskel, S.; Brunner, E. Bioinspired carbide-derived carbons with hierarchical pore structure for the adsorptive removal of mercury from aqueous solution. Chem. Commun. 2017, 53, 4845-4848. [CrossRef] [PubMed]

126. Yachamaneni, S.; Yushin, G.; Yeon, S.H.; Gogotsi, Y.; Howell, C.; Sandeman, S.; Phillips, G.; Mikhalovsky, S. Mesoporous carbide-derived carbon for cytokine removal from blood plasma. Biomaterials 2010, 31, 4789-4794. [CrossRef] [PubMed]

127. Borchardt, L.; Oschatz, M.; Kaskel, S. Tailoring porosity in carbon materials for supercapacitor applications. Mater. Horiz. 2014, 1, 157-168. [CrossRef]

128. Borchardt, L.; Oschatz, M.; Kaskel, S. Carbon materials for lithium sulfur batteries-ten critical questions. Chem. Eur. J. 2016, 22, 7324-7351. [CrossRef] [PubMed] 
129. Ren, X.; Li, H.; Chen, J.; Wei, L.; Modak, A.; Yang, H.; Yang, Q. N-doped porous carbons with exceptionally high $\mathrm{CO}_{2}$ selectivity for $\mathrm{CO}_{2}$ capture. Carbon 2017, 114, 473-481. [CrossRef]

130. Lai, F.; Feng, J.; Yan, R.; Wang, G.-C.; Antonietti, M.; Oschatz, M. Breaking the limits of ionic liquid-based supercapacitors: Mesoporous carbon electrodes functionalized with manganese oxide nanosplotches for dense, stable, and wide-temperature energy storage. Adv. Funct. Mater. 2018, 28, 1801298. [CrossRef]

131. Krüner, B.; Schreiber, A.; Tolosa, A.; Quade, A.; Badaczewski, F.; Pfaff, T.; Smarsly, B.M.; Presser, V. Nitrogen-containing novolac-derived carbon beads as electrode material for supercapacitors. Carbon 2018, 132, 220-231. [CrossRef]

132. Wei, L.; Sevilla, M.; Fuertes, A.B.; Mokaya, R.; Yushin, G. Polypyrrole-derived activated carbons for high-performance electrical double-layer capacitors with ionic liquid electrolyte. Adv. Funct. Mater. 2012, 22, 827-834. [CrossRef]

133. Yin, L.-C.; Liang, J.; Zhou, G.-M.; Li, F.; Saito, R.; Cheng, H.-M. Understanding the interactions between lithium polysulfides and N-doped graphene using density functional theory calculations. Nano Energy 2016, 25, 203-210. [CrossRef]

134. Hippauf, F.; Nickel, W.; Hao, G.-P.; Schwedtmann, K.; Giebeler, L.; Oswald, S.; Borchardt, L.; Doerfler, S.; Weigand, J.J.; Kaskel, S. The importance of pore size and surface polarity for polysulfide adsorption in lithium sulfur batteries. Adv. Mater. Interfaces 2016, 3, 1600508. [CrossRef]

135. Song, J.; Gordin, M.L.; Xu, T.; Chen, S.; Yu, Z.; Sohn, H.; Lu, J.; Ren, Y.; Duan, Y.; Wang, D. Strong lithium polysulfide chemisorption on electroactive sites of nitrogen-doped carbon composites for high-performance lithium-sulfur battery cathodes. Angew. Chem. Int. Ed. 2015, 54, 4325-4329. [CrossRef] [PubMed]

136. Su, D.S.; Zhang, J.; Frank, B.; Thomas, A.; Wang, X.; Paraknowitsch, J.; Schlogl, R. Metal-free heterogeneous catalysis for sustainable chemistry. ChemSusChem 2010, 3, 169-180. [CrossRef] [PubMed]

137. Li, X.H.; Antonietti, M. Metal nanoparticles at mesoporous n-doped carbons and carbon nitrides: Functional mott-schottky heterojunctions for catalysis. Chem. Soc. Rev. 2013, 42, 6593-6604. [CrossRef] [PubMed]

138. Su, H.; Zhang, K.X.; Zhang, B.; Wang, H.H.; Yu, Q.Y.; Li, X.H.; Antonietti, M.; Chen, J.S. Activating cobalt nanoparticles via the mott-schottky effect in nitrogen-rich carbon shells for base-free aerobic oxidation of alcohols to esters. J. Am. Chem. Soc. 2017, 139, 811-818. [CrossRef] [PubMed]

139. Vile, G.; Albani, D.; Nachtegaal, M.; Chen, Z.; Dontsova, D.; Antonietti, M.; Lopez, N.; Perez-Ramirez, J. A stable single-site palladium catalyst for hydrogenations. Angew. Chem. Int. Ed. 2015, 54, 11265-11269. [CrossRef] [PubMed]

140. Sevilla, M.; Foulston, R.; Mokaya, R. Superactivated carbide-derived carbons with high hydrogen storage capacity. Energy Environ. Sci. 2010, 3, 223-227. [CrossRef]

141. Chmiola, J.; Yushin, G.; Gogotsi, Y.; Portet, C.; Simon, P.; Taberna, P.L. Anomalous increase in carbon capacitance at pore sizes less than 1 nanometer. Science 2006, 313, 1760-1763. [CrossRef] [PubMed]

142. Sigalov, S.; Levi, M.D.; Salitra, G.; Aurbach, D.; Jänes, A.; Lust, E.; Halalay, I.C. Selective adsorption of multivalent ions into tic-derived nanoporous carbon. Carbon 2012, 50, 3957-3960. [CrossRef]

143. Heon, M.; Lofland, S.; Applegate, J.; Nolte, R.; Cortes, E.; Hettinger, J.D.; Taberna, P.-L.; Simon, P.; Huang, P.; Brunet, M.; et al. Continuous carbide-derived carbon films with high volumetric capacitance. Energy Environ. Sci. 2011, 4, 135-138. [CrossRef]

144. Wuttke, S.; Medina, D.D.; Rotter, J.M.; Begum, S.; Stassin, T.; Ameloot, R.; Oschatz, M.; Tsotsalas, M. Bringing porous organic and carbon-based materials toward thin-film applications. Adv. Funct. Mater. 2018, 1801545. [CrossRef]

145. Gao, Y.; Presser, V.; Zhang, L.; Niu, J.J.; McDonough, J.K.; Pérez, C.R.; Lin, H.; Fong, H.; Gogotsi, Y. High power supercapacitor electrodes based on flexible tic-cdc nano-felts. J. Power Sources 2012, 201, 368-375. [CrossRef]

146. Rose, M.; Kockrick, E.; Senkovska, I.; Kaskel, S. High surface area carbide-derived carbon fibers produced by electrospinning of polycarbosilane precursors. Carbon 2010, 48, 403-407. [CrossRef]

147. Borchardt, L.; Leistenschneider, D.; Haase, J.; Dvoyashkin, M. Revising the concept of pore hierarchy for ionic transport in carbon materials for supercapacitors. Adv. Energy Mater. 2018, 8, 1800892. [CrossRef]

148. Schönherr, A. Boehm titration revisited (part i): Practical aspects for achieving a high precision in quantifying oxygen-containing surface groups on carbon materials. C 2018, 4, 21. [CrossRef] 
149. Schönherr, J.; Buchheim, J.; Scholz, P.; Adelhelm, P. Boehm titration revisited (part ii): A comparison of boehm titration with other analytical techniques on the quantification of oxygen-containing surface groups for a variety of carbon materials. C 2018, 4, 22. [CrossRef]

150. Leistenschneider, D.; Zürbes, K.; Schneidermann, C.; Grätz, S.; Oswald, S.; Wegner, K.; Klemmed, B.; Giebeler, L.; Eychmüller, A.; Borchardt, L. Mechanochemical functionalization of carbon black at room temperature. C 2018, 4, 14. [CrossRef]

151. Xing, R.; Zhou, Y.; Ma, R.; Liu, Q.; Luo, J.; Yang, M.; Wang, J. Nitrogen-doped hollow carbon spheres with embedded co nanoparticles as active non-noble-metal electrocatalysts for the oxygen reduction reaction. $C$ 2018, 4, 11. [CrossRef]

152. Seredych, M.; Mikhalovska, L.; Mikhalovsky, S.; Gogotsi, Y. Adsorption of bovine serum albumin on carbon-based materials. C 2018, 4, 3. [CrossRef]

153. Moo, J.; Omar, A.; Jaumann, T.; Oswald, S.; Balach, J.; Maletti, S.; Giebeler, L. One-pot synthesis of graphene-sulfur composites for li-s batteries: Influence of sulfur precursors. C 2017, 4, 2. [CrossRef]

(C) 2018 by the authors. Licensee MDPI, Basel, Switzerland. This article is an open access article distributed under the terms and conditions of the Creative Commons Attribution (CC BY) license (http:/ / creativecommons.org/licenses/by/4.0/). 